Research Paper No. 2004/2

\title{
How Does Monetary Policy Affect the Poor? Evidence from the West African Economic and Monetary Union
}

\section{David Fielding*}

January 2004

\begin{abstract}
The West African Economic and Monetary Union (UEMOA) has a history of monetary stability and low inflation. Nevertheless, there is substantial variation in relative prices within some UEMOA countries, in particular in the price of food relative to other elements of the retail price index (IHPC). Using monthly time-series data for cities within the region, we analyze the impact of changes in monetary policy instruments on the relative prices of components of the IHPC. We are then able to explore how the burden of monetary policy innovations is likely to be shared between the rich and poor.
\end{abstract}

Keywords: monetary policy, poverty, Africa

JEL classification: E52, I39, O23

Copyright (C) UNU-WIDER 2004

* Department of Economics, University of Leicester, and UNU-WIDER.

This study has been prepared within the UNU-WIDER project on 'Long-Term Development in the CFAzone Countries of sub-Saharan Africa', directed by David Fielding.

UNU-WIDER gratefully acknowledges the financial contribution to the project by the Finnish Ministry for Foreign Affairs.

UNU-WIDER also acknowledges the financial contributions to the research programme by the governments of Denmark (Royal Ministry of Foreign Affairs), Norway (Royal Ministry of Foreign Affairs), Sweden (Swedish International Development Cooperation Agency - Sida) and the United Kingdom (Department for International Development). 


\section{Acknowledgements}

I would like to thank Jean-Paul Azam and participants at a UNU-WIDER workshop for comments on a previous draft of this paper, but all remaining errors are mine.

The World Institute for Development Economics Research (WIDER) was established by the United Nations University (UNU) as its first research and training centre and started work in Helsinki, Finland in 1985. The Institute undertakes applied research and policy analysis on structural changes affecting the developing and transitional economies, provides a forum for the advocacy of policies leading to robust, equitable and environmentally sustainable growth, and promotes capacity strengthening and training in the field of economic and social policy making. Work is carried out by staff researchers and visiting scholars in Helsinki and through networks of collaborating scholars and institutions around the world.

www.wider.unu.edu

publications@wider.unu.edu

UNU World Institute for Development Economics Research (UNU-WIDER)

Katajanokanlaituri 6 B, 00160 Helsinki, Finland

Camera-ready typescript prepared by Janis Vehmaan-Kreula at UNU-WIDER

Printed at UNU-WIDER, Helsinki

The views expressed in this publication are those of the author(s). Publication does not imply endorsement by the Institute or the United Nations University, nor by the programme/project sponsors, of any of the views expressed. 


\section{Introduction}

Most papers in applied monetary economics are concerned with aggregate macroeconomic data, and ignore the possible consequences of monetary policy interventions for income distribution and poverty. This is true not only of papers about OECD countries, but also of papers about developing economies. There are some exceptions. Romer and Romer (1998) and Easterly and Fischer (2000) look at the crosscountry correlation between aggregate inflation and the well being of the poor, finding that on average low inflation enhances welfare. Similar conclusions arise from the case studies in Ganuza and Taylor (1998). Another group of papers, including Cardoso (1992), Cobham (2001) and Azam (2003), look at the impact of different types of macroeconomic policy reform - such as orthodox stabilization packages, capital account liberalization and nominal exchange rate devaluation - on poverty.

A common theme in many of these papers is an emphasis on extreme contrasts (such as the difference between countries with hyperinflation and those with moderate inflation) or on the extreme policy interventions associated with macroeconomic policy reform that were so common in developing countries in the 1980s and 1990s. They have less to say about the impact of 'day to day' monetary policy on poverty. In countries that now have a relatively low and stable rate of inflation, and a manageable budget deficit, how do alternative types of monetary policy intervention affect the poor? Often, when looking at large, secular changes in the inflation rate, the focus of attention is on the adjustment of wages and on unemployment. But alternative short-term stabilization policy rules that impact on the prices of different commodities in different ways could also have very different consequences for the welfare of the poor. Even at very short horizons, over which wages are fixed, variations in prices could have a substantial impact on welfare. For example, some types of policy could be associated with relatively high variation in the prices of commodities (such as food) that make up a large fraction of the consumption of poorer households.

Why might this be so? Consider the possible differences between the impact of a change in interest rates and a change in the volume currency issued (still a potentially effective monetary policy tool in countries where financial markets are underdeveloped and M0 makes up a large fraction of the total money stock). M0 is a poor person's financial asset. An expansion of the currency stock will generate excess liquidity predominantly among the poor, and relatively more inflation in the prices of commodities consumed mostly by the poor. By contrast, the interest elasticity of saving is not likely to be much higher among the poor than it is among the rich. (In some developing countries it has been very low among all income groups.) So a reduction in the interest rate is less likely to generate more inflation among the commodities consumed mostly by the poor. Even if the prices of different commodities are cointegrated in the long run, inertia in the price convergence process might mean that short-run asymmetries of this kind are substantial.

The picture becomes even more complex if increases in liquidity stimulate a positive agricultural supply response in the short run, and cause an initial reduction in food prices. This is possible if, for example, aggregate prices are slow to rise in response to an increase in the nominal money stock, so there is an increase in the level of private sector real wealth. If people want to maintain a fixed wealth-income ratio, this may stimulate a reduction in the holding of other assets, including storable agricultural commodities. 
It is quite possible that alternative types of monetary policy intervention that have the same aggregate effect - on for example the aggregate consumer price index - have very different types of effect on the components of this index, and therefore on the volatility of prices faced by different income groups. By a similar argument, there could be substantial regional asymmetries in the effects of different types of policy. In this paper we will explore these issues with respect to one particular area, the West African Economic and Monetary Union (UEMOA).

The UEMOA is a suitable area in which to address these questions because it has a history of a low and stable rate of inflation. The currency of the monetary union, the CFA Franc issued by the Central Bank of West African States (BCEAO), ${ }^{1}$ has long been pegged to the French Franc (and now the Euro) at a fixed rate, with only a single devaluation since 1948. This devaluation (of 100 per cent) occurred in January 1994, and one Euro is now worth 657 CFA Francs. Aside from the first few months of 1994,2 inflation in the member states of the UEMOA has been comparable with that of France. 3 Commitment to the fixed peg by a transnational central bank makes a low long-run rate of monetary expansion a time-consistent policy. The questions about poverty surrounding the comparison of low and high-inflation regimes are not relevant here. But the formulation of welfare-enhancing short-term monetary policy ought to be informed by the impact of such policy on the poor. Moreover, the relatively high-quality monetary data provided by the BCEAO makes such a study feasible.

In addition, the existence of regional price data within the UEMOA makes it possible to determine whether there are any regional asymmetries in the impact of monetary policy. The area has a single central bank issuing a single currency; but regional differences in, for example, the magnitude of short-run price inertia might mean that a monetary policy intervention has very different effects in different regions.

These issues will be addressed by fitting a time-series model of regional food and nonfood prices to data from the UEMOA. The structure of this model is elaborated in the following section.

\section{Conceptual overview}

The aim of the paper is to trace out the impact of monetary policy interventions on the price of the food and non-food components of the retail price index for urban consumers in different locations in the UEMOA. In this way, we can examine the effect of policy changes on the cost of living of different hypothetical income groups, among whom food consumption makes up a different proportion of total expenditure.

BCEAO monthly price statistics (discussed in more detail in the next section) are available for the principal cities of seven out of the eight countries that make up the

1 This is not to be confused with the CFA Franc issued by the Bank of Central African States (BEAC), an entirely different currency in a monetary area outside the scope of this paper.

2 Azam (2003) deals with the consequences of the devaluation episode for poverty in the UEMOA.

3 Although there is no evidence for PPP in levels between France and the UEMOA (Nuven 1994). 
UEMOA: Benin, Burkina Faso, Côte d'Ivoire, Mali, Niger, Senegal and Togo.4 (Data for Guinea-Bissau, which joined the monetary union in 1997, are not available.) Our econometric model will make use of these data. We will be focussing on the postdevaluation period (1994-2002). The 100 per cent devaluation of the CFA Franc in January 1994 represented a substantial structural break in the DGP for prices across the UEMOA, and it turned out not to be possible to fit a model with stable parameters to a data set incorporating the break period.

In this section, we provide an overview of the modeling framework to be employed. This framework is based on several key assumptions.

The first underlying assumption of the model (which will later be tested) is that there is long-run cointegration between the logarithms of food and non-food prices ( $p^{f}$ and $p^{r}$ ) in each country $i$, each of which is integrated $\mathrm{I}(1)$. Moreover, there is long-run cointegration between the price of food in country $i$ and the price of food in any of the other countries; the same is true of the non-food aggregate. However, prices differ from each other in the short run because they are subjected to shocks $\left(\varepsilon_{i t}^{z}, z=(f, r)\right)$ that are not perfectly correlated. These shocks include local variations in productivity and in the cost of imports (the share of different commodities in total imports varying from one country to another).

The process of equilibrium correction could take a number of forms. In the UMEOA, one country (Côte d'Ivoire) is very much larger than the rest, and there is a substantial amount of migration between many of the smaller countries and Ivorian cities. 5 We will assume that Côte d'Ivoire is a 'lead' country, in the sense that prices in other countries all eventually converge on those in Côte d'Ivoire, but Ivorian prices are not affected by prices in the smaller countries, at least in the long run. (This assumption will be tested later.) In the absence of any changes in income, the money supply or interest rates, prices in each of the smaller countries $(i)$ evolve according to an equilibrium correction process of the form:

$$
\begin{aligned}
\beta_{i}^{f}(L) \Delta p_{i t}^{f} & =\mu_{i t}^{f}+\sum_{z} \sum_{j \neq i} \theta_{j}^{z f}(L) \Delta p_{j t-1}^{z}+\theta_{i}^{f}(L) \Delta p_{i t-1}^{r} \\
& -\gamma_{i 0}^{f}\left[p_{i t-1}^{f}-p_{i t-1}^{r}\right]-\gamma_{i 1}^{f}\left[p_{i t-1}^{f}-p_{C V V t-1}^{f}\right]-\gamma_{i 2}^{f}\left[p_{i t-1}^{r}-p_{C V V t-1}^{r}\right]+\varepsilon_{i t}^{f} \\
\beta_{i}^{r}(L) \Delta p_{i t}^{r} & =\mu_{i t}^{r}+\sum_{z} \sum_{j \neq i} \theta_{j}^{z r}(L) \Delta p_{j t-1}^{z}+\theta_{i}^{r}(L) \Delta p_{i t-1}^{f} \\
& -\gamma_{i 0}^{r}\left[p_{i t-1}^{f}-p_{i t-1}^{r}\right]-\gamma_{i 1}^{r}\left[p_{i t-1}^{f}-p_{C I V t-1}^{f}\right]-\gamma_{i 2}^{r}\left[p_{i t-1}^{r}-p_{C I V t-1}^{r}\right]+\varepsilon_{i t}^{r}
\end{aligned}
$$

where the $\beta_{i}(L)$ and $\theta_{i}(L)$ terms are lag operators and the $\mu_{i t}$ terms represent a set of deterministic components in the process. The time domain $t$ is measured in months. We expect the signs and sizes of the $\gamma$ parameters to be consistent with the long-run stability of the system with full price convergence, but do not impose any structure on

4 That is, Cotonou, Ougadougou, Abidjan, Bamako, Niamey, Dakar and Lomé.

5 See Appleyard (1999) for a description of migration patterns in the area. 
the short-run dynamics captured by the $\beta_{i}(L)$ and $\theta_{i}(L)$ terms. In the short run, prices in country $i$ could be especially sensitive to prices in one or more of the other countries. Equations (1-2) can also be re-parameterized as:

$$
\begin{aligned}
\beta_{i}^{f}(L) \Delta p_{i t}^{f} & =\mu_{i t}^{f}+\sum_{z} \sum_{j \neq i} \theta_{j}^{z f}(L) \Delta p_{j t-1}^{z}+\theta_{i}^{f}(L) \Delta p_{i t-1}^{r} \\
& -\eta_{i 0}^{f}\left[p_{C I V t-1}^{f}-p_{C I V t-1}^{r}\right]-\eta_{i 1}^{f}\left[p_{i t-1}^{f}-p_{C I V t-1}^{f}\right]-\eta_{i 2}^{f}\left[p_{i t-1}^{r}-p_{C I V t-1}^{r}\right]+\varepsilon_{i t}^{f} \\
\beta_{i}^{r}(L) \Delta p_{i t}^{r} & =\mu_{i t}^{r}+\sum_{z} \sum_{j \neq i} \theta_{j}^{z r}(L) \Delta p_{j t-1}^{z}+\theta_{i}^{r}(L) \Delta p_{i t-1}^{f} \\
& -\eta_{i 0}^{r}\left[p_{C I V t-1}^{f}-p_{C I V t-1}^{r}\right]-\eta_{i 1}^{r}\left[p_{i t-1}^{f}-p_{C I V t-1}^{f}\right]-\eta_{i 2}^{r}\left[p_{i t-1}^{r}-p_{C I V t-1}^{r}\right]+\varepsilon_{i t}^{r}
\end{aligned}
$$

where the first equilibrium correction term includes only Ivorian prices. Note that in the 'lead' country, Côte d'Ivoire, only the first equilibrium correction term enters into the price equations. The last two equilibrium correction terms are equal to zero by construction.

How do changes in monetary policy affect prices? In this paper we consider the possible influence of two policy instruments, the stock of currency in circulation in the UEMOA $(m)$ and the BCEAO base interest rate $(r)$. The impact of changes in $m$ on prices will depend on its interaction with other monetary aggregates. There is some evidence that there is a stable real M1 demand function (that is, demand for $m$ plus checking deposits) across the monetary area, if we allow for an exogenous structural break in the devaluation year, 1994.6 Moreover, there are few legal restrictions on checking deposits. So, if checking deposits are a close substitute for currency, any increase in $m$ will (at least partially) be offset by a reduction in deposits, ceteris paribus. In this case, there will be no stable long-run relationship between the real value of currency and the determinants of demand for M1 (real income and interest rates).

This appears to be the case. If we use annual data for the pre-devaluation period (196493), it is not possible to reject the hypothesis that there is no long-run relationship between the real value of currency, income and the interest rate. We conducted a test for the existence of such a relationship using real GDP as an income measure for the seven UEMOA countries (excluding Guinea-Bissau), and constructing an aggregate UEMOA price series as the GDP-weighted average of national GDP deflators. (Consumer price indices are not available for all countries before 1970.) The test follows the method of Pesaran et al. (2001), which does not require a priori knowledge about the order of integration of the series. It is constructed as an F-statistic for the joint significance of the $\theta$ parameters in the regression:

$$
\begin{aligned}
\beta(L) \Delta(m-p)_{t} & =\alpha_{0}+\alpha_{1} \cdot t+\gamma(L) \Delta y_{t}+\delta(L) \Delta r_{t} \\
& -\theta_{0} \cdot(m-p)_{t-1}+\theta_{1} \cdot y_{t-1}+\theta_{2} \cdot r_{t-1}+u_{t}
\end{aligned}
$$

6 See for example Sugimoto (2001). 
where $p_{t}$ is the aggregate deflator, $y_{t}$ is aggregate real income, $r_{t}$ is the (base) interest rate and $u_{t}$ a residual. There is a range of critical values for the F-statistic, depending on the (unknown) order of integration of the different series. Using a lag order of one (which optimizes the Hannan-Quinn and Akaike criteria for the regression), our computed F-statistic is 2.90, which falls below the lower bound of these critical values. In other words, regardless of the order of integration of the series, we cannot reject the null that there is no long-run relationship. ${ }^{7}$ If the sample is extended beyond 1993, there is still no evidence for a long-run relationship, and the regression parameters become unstable.

For this reason, we model the impact of monetary policy on prices in the postdevaluation period without cointegration between $(m-p)$ and the determinants of demand for real M1. We allow for the possibility that changes in $m$ or $r$ have an immediate direct impact on prices, before the volume of checking deposits has time to adjust. But in the long run there is no stable relationship between the price level and the level of currency. This model encompasses as a special case the situation in which deposits adjust instantaneously to a change in the volume of currency, in which case such changes have no impact on prices, even in the short run. However, this case is $a$ priori unlikely. In many parts of West Africa, informal sector agents intermediate between poor households and the formal banking sector. The intermediaries hold assets with respect to the formal banking sector (in the form of bank deposits) and liabilities with respect to households. In this kind of market it is likely that an injection of cash into the economy will lead to an adjustment of bank deposits only with a lag of some months.

More formally, we amend equations (3-4) as follows:

$$
\begin{aligned}
\beta_{i}^{f}(L) \Delta p_{i t}^{f} & =\mu_{i t}^{f}+\sum_{z} \sum_{j \neq i} \theta_{j}^{z f}(L) \Delta p_{j t-1}^{z}+\theta_{i}^{f}(L) \Delta p_{j t-1}^{r}+\phi_{i}^{f} \Delta m_{t-1}+\psi_{i}^{f} \Delta r_{t-1} \\
& -\eta_{i 0}^{f}\left[p_{C I V t-1}^{f}-p_{C I V t-1}^{r}\right]-\eta_{i 1}^{f}\left[p_{i t-1}^{f}-p_{C I V t-1}^{f}\right]-\eta_{i 2}^{f}\left[p_{i t-1}^{r}-p_{C I V t-1}^{r}\right]+\varepsilon_{i t}^{f} \\
\beta_{i}^{r}(L) \Delta p_{i t}^{r} & =\mu_{i t}^{r}+\sum_{z} \sum_{j \neq i} \theta_{j}^{z r}(L) \Delta p_{j t-1}^{z}+\theta_{i}^{r}(L) \Delta p_{j t-1}^{f}+\phi_{i}^{r} \Delta m_{t-1}+\psi_{i}^{r} \Delta r_{t-1} \\
& -\eta_{i 0}^{r}\left[p_{C I V t-1}^{f}-p_{C I V t-1}^{r}\right]-\eta_{i 1}^{r}\left[p_{i t-1}^{f}-p_{C I V t-1}^{f}\right]-\eta_{i 2}^{r}\left[p_{i t-1}^{r}-p_{C I V t-1}^{r}\right]+\varepsilon_{i t}^{r}
\end{aligned}
$$

where $m_{t}$ is the value of the stock of currency in circulation at the end of month $t$, and $r_{t}$ is the base interest rate at the end of month $t$. Note that a permanent change in $m$ can have a permanent impact on the price level. If more cash is injected into the economy, then ceteris paribus prices will start to rise and deposits will start to fall. But there is likely to be inertia in both. Given the initial rise in prices, and a fixed real demand for M1, the eventual fall in deposits will be less than the initial cash injection. So the long run will see a larger total nominal money stock and higher prices, but the price increase is less than proportional to the initial cash injection. There is no stable long-run ratio of the volume of cash to the price level, even when we condition on determinants of money demand such as the interest rate.

7 This is still true if we exclude the interest rate from the regression. 
One important caveat in the interpretation of the fitted model is that there is no variable in equations (6-7) to capture changes in real income. GDP data for the UEMOA countries are reported only on an annual basis, and we will be fitting a monthly model. However, over the relatively short period of 8 years that we will be considering, it is likely that variations in monthly income are dominated by the seasonal agricultural cycle. No large income shocks appear in the annual GDP data for the period. So the seasonal and trend components of $\mu_{i t}^{z}$ in the regression equations ought to be a reasonable proxy for the income variable.

The policy variables $m$ and $r$ appear in the regression equations with a lag: they represent the value of the variable at the end of the month before the price index is observed. The values of policy variables are determined by the BCEAO on a monthly basis, and the raw data for the price indices are collected on a monthly basis (the process of data collection is often stretched over several weeks within the month). So the frequency of observations in the model matches the frequency with which the variables are observed. Since $m_{t-1}$ and $r_{t-1}$ are predetermined variables, they are weakly exogenous to prices at $t$, and the parameters $\phi_{i}$ and $\psi_{i}$ can be estimated consistently without recourse to an instrumental variables estimator. Of course they might not be strictly exogenous, since BCEAO policy interventions might well depend on observed inflation. Fielding (1999) and Shortland and Stasavage (2003a,b) explore this issue.

One potential problem in interpreting a model of the kind represented by equations (6-7) is that the estimated effect of $\Delta m$ on prices might be partly due to a correlation between $\Delta m$ and public expenditure. For example, one might worry that food subsidies (such as those introduced in many UEMOA countries in the wake of the devaluation) are correlated with public spending, which is in turn correlated with money creation. In this case there is no straightforward interpretation of the estimated effect of $\Delta m$ on prices. However, the BCEAO has a number of financial instruments (for example, foreign liabilities) with which it can sterilize the impact of short-run fluctuations in government borrowing on money creation (Fielding 1999). The correlation coefficient for deseasonalized $\Delta m$ and the deseasonalized rate of growth of BCEAO claims on governments in our sample period $(1994 \mathrm{~m} 4-2002 \mathrm{~m} 7)$ is only 0.178 .8 So we can be reasonably sure that the estimated coefficient on $\Delta m$ does not suffer from any substantial bias from a correlation between $\Delta m$ and public spending.

Having fitted the model represented by equations (6-7) to our monthly data, we will be in a position to map out the way in which individual prices series respond to a change in $m$ or $r$. Before explaining how this is done, it should be noted that our aim is to explore the impact of changes in policy on prices, rather than to model policy and prices simultaneously. We will use the fitted model parameters to compute the impact of a change in a policy variable on prices, conditional on the assumption that the policy variable does not change again in response to the price changes. In this sense, the policy variable changes we explore are not intended to represent 'typical' historical policy episodes. Rather, we investigate the consequences of monetary policy interventions

8 The corresponding t-ratio is 1.801 , so there is a marginally significant (but very small) correlation between the two variables. 
from the point of view of the policymaker, treating the policy change as a strictly exogenous event. 9

In section 4, we will first present the fitted model of prices. We will then examine the implications of the model for the way in which food and non-food prices in each country evolve in response to changes in the currency stock or in the base interest rate. The focus of attention will be on the first 12 months after the change in policy, since we think it unlikely that any policy maker will work with a time horizon longer than a year. Though the pattern of food and non-food price responses is of interest in itself, one way of expanding on the implications of the results is to plot out the response of aggregate price indices of different kinds. The share food in the consumption of households with higher incomes is likely to be lower than that of lower income households. We will construct price response profiles for hypothetical households with different shares of food expenditure in total consumption. In this way, we can explore the possibility that households at different income levels are affected by monetary policy changes in an asymmetric way. We can also explore any regional asymmetries in the effects of changes in $m$ and $r$.

\section{The data10}

\subsection{Overview}

Monthly data for the 14 price series $p_{i t}^{z}$ are reported in the BCEAO publication, Indices Hamonisés des Prix à la Consommation des Etats de l'Union Economique et Monétaire Ouest Africaine. The corresponding monthly inflation series are depicted in Figures 1 and 2. These are sub-components of the harmonized index of consumer prices (IHPC). The weights given to the two components in the IHPC vary from one country to another, but always sum to unity. The largest weight on food prices (0.5001) is in Mali; the lowest $(0.3221)$ is in Côte d'Ivoire. This reflects a substantial difference in per capita GDP between the two countries: 0.166 million CFA Francs in Mali $(€ 255)$ and 0.421 million CFA Francs (€640) in Côte d'Ivoire in 2001. The effect of the 1994 devaluation is very marked in many of the inflation series, particularly in $\Delta p_{i t}^{r}$, and the distribution of inflation over a sample including early 1994 is markedly leptokurtic. We do not attempt to model the devaluation episode, and our sample period begins in $1994 \mathrm{~m} 4$ and ends in $2002 \mathrm{~m} 7$. It can be seen from the figures that over this period food prices have been markedly more volatile than non-food prices. We will see whether this difference is associated with varying degrees of sensitivity to monetary policy.

9 Thus we are not directly concerned with impact of monetary policy shocks. Our aim is not to identify the consequences of unpredictable changes in monetary policy variables, but rather to inform policy by estimating the consequences of a planned policy change. We do make the assumption that the impact of unpredictable changes in $m$ and $r$ is the same as the impact of predictable changes; when looking at data at a monthly frequency, this seems to us to be a reasonable assumption.

10 All results reported in this and the following section were produced using Pc-Give 9.0 and Pc-Fiml 9.0 . 
Monthly data for $m_{t}$ and $r_{t}$ are taken from the IMF International Financial Statistics, lines $14 \mathrm{~A}$ and 60 respectively. Note that $r_{t}$ is the monthly annualized interest rate. The IMF reports M0 figures for each individual country, because CFA notes are issued by national branches of the BCEAO. But these notes differ only by serial number, and circulate freely in all countries of the UEMOA. The $m_{t}$ series used in the fitted model is the logarithm of the sum of these 'national' currency stocks. 11 Figure 3 illustrates the two series. It can be seen that there is a great deal of seasonal variation in $m_{t}$; this is because cash is one of the principal financial assets used by farmers to smooth consumption over the agricultural cycle. The BCEAO allows the stock of currency in circulation to vary over the year to match the seasonal variations money demand. For this reason the seasonal component of $\mu_{i t}^{z}$ explains a large part of the variation in prices conditional on $m_{t}$. As Figure 3 shows, the seasonal pattern is very regular. There is also a marked break in the $m_{t}$ series after the devaluation in January 1994: since the devaluation, the money stock has been allowed to expand at a much faster rate.

Figure 1: Monthly urban food price inflation in the UEMOA
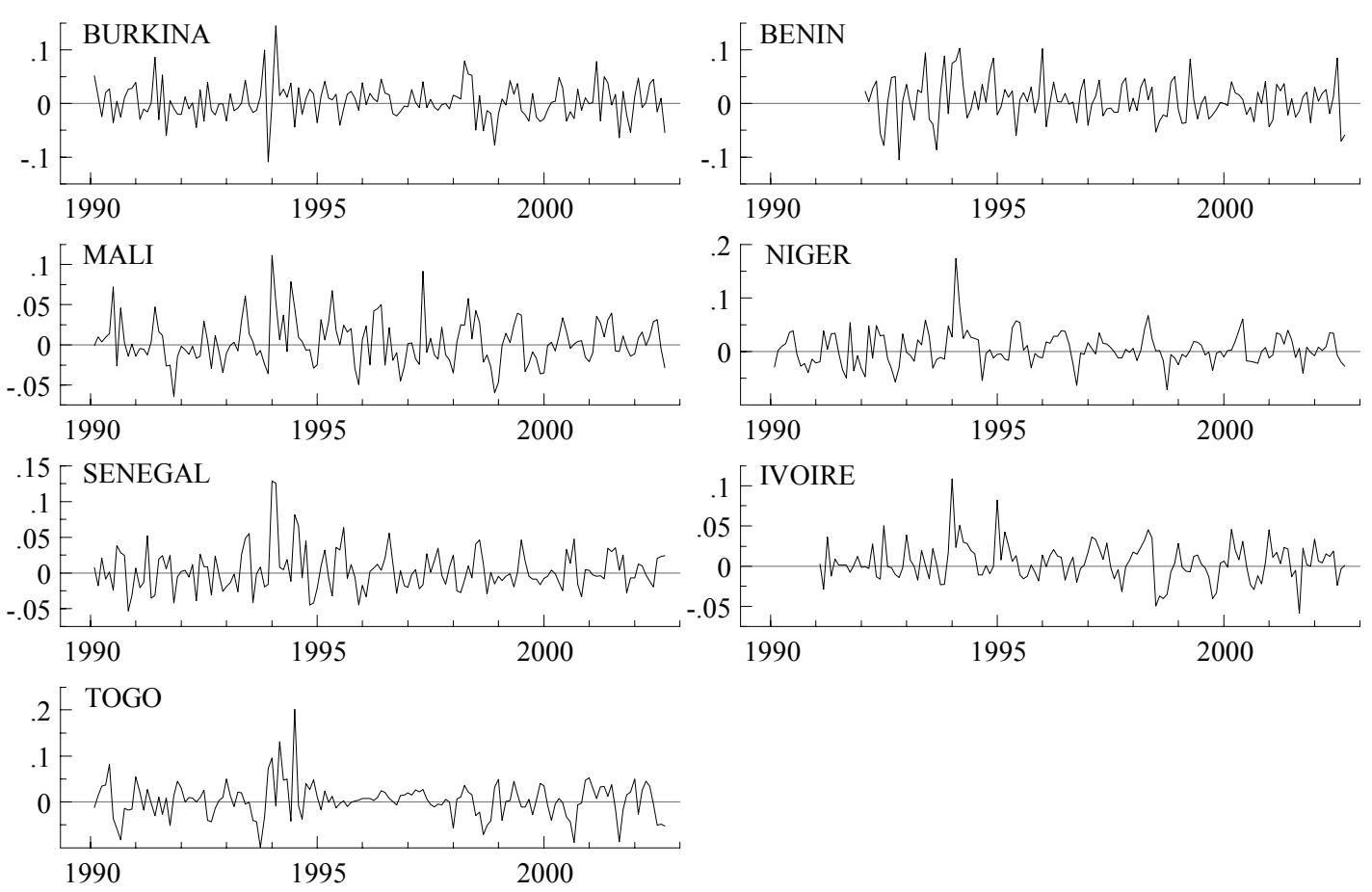

11 Data on the cross-border movement of notes are limited. The BCEAO makes periodic attempts to track the billets déplacés, figures for which are sometimes reported in the Rapport Annuel de la Zone Franc, published by the Banque de France. These indicate that a substantial fraction of the currency issued travels from one country to another. 
Figure 2: Monthly urban non-food price inflation in the UEMOA
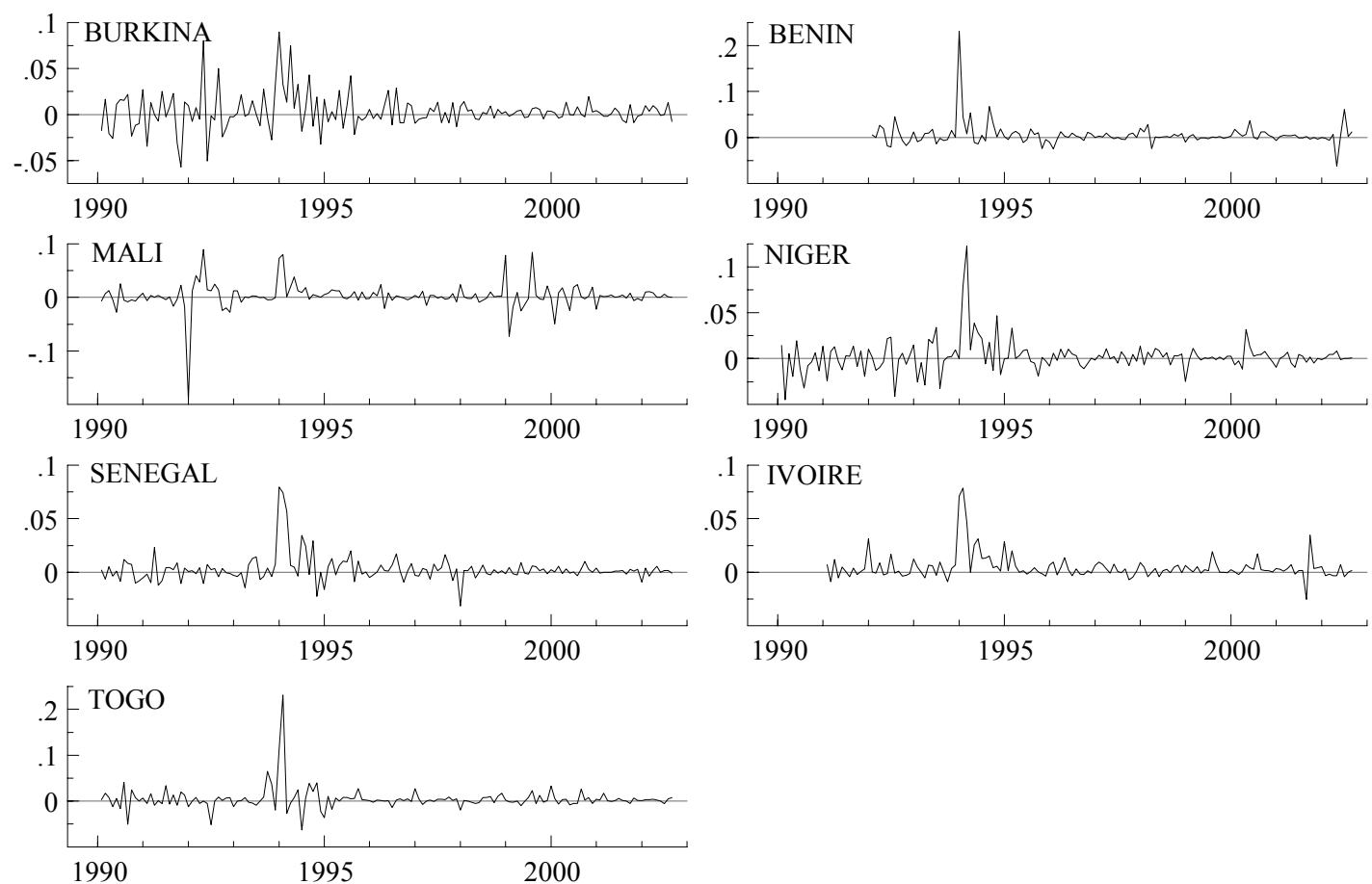

Figure 3: BCEAO nominal M0 and base interest rate, 1990-2002
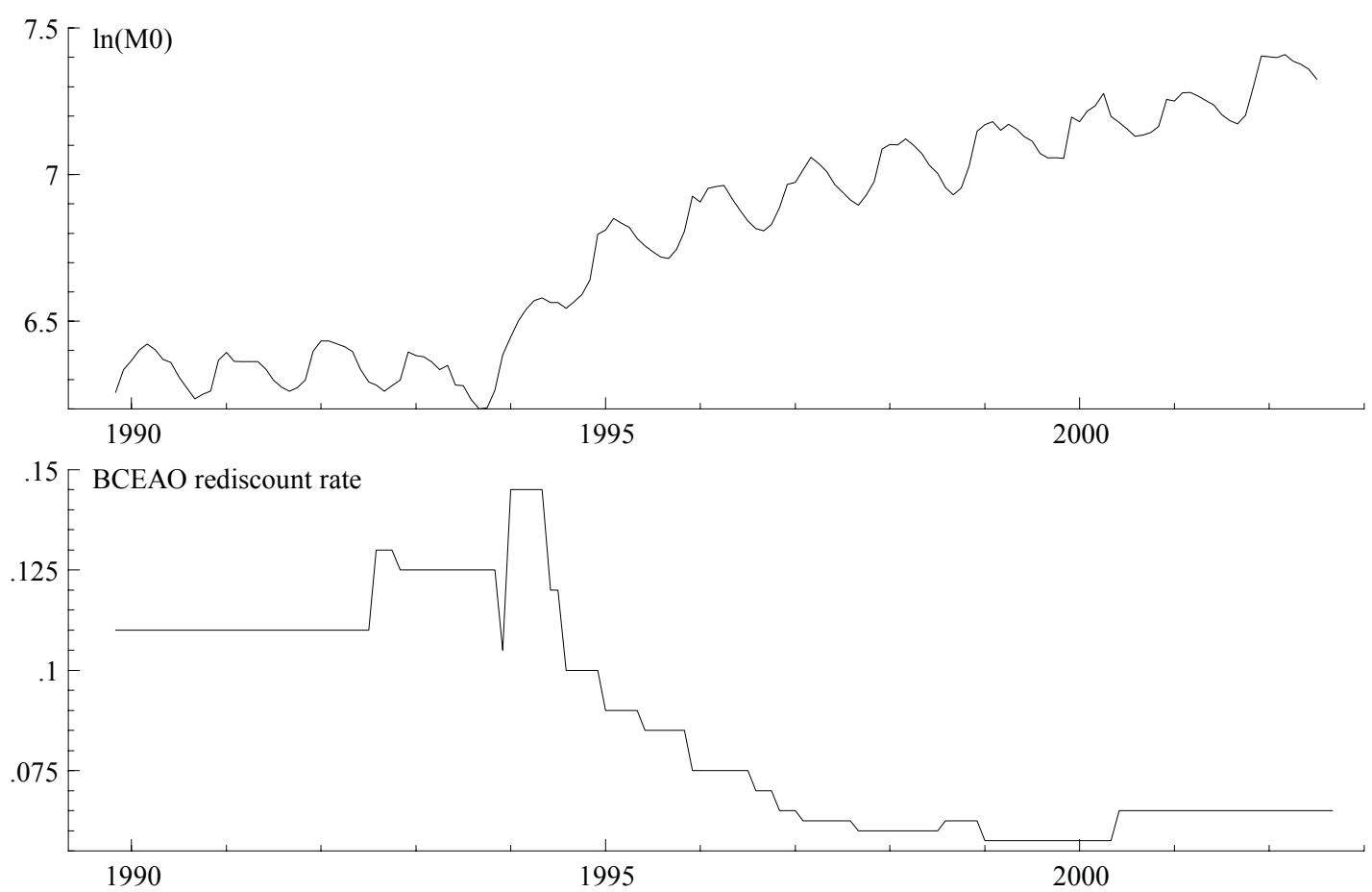
Table 1

Tests for stationarity

The sample is 1994(4)-2002(9) for prices; 1994(4)-2002(7) for $m$ and $r$.

Individual $A D F$ t-statistics for differenced variables ( $A D F$ regressions include seasonal intercepts but no trend)

\begin{tabular}{|c|c|c|c|c|c|c|}
\hline & & & & & & \\
\hline & $A D F \quad t$ & $\operatorname{lag}$ & order & $A D F \quad t$ & $\operatorname{lag}$ & order \\
\hline Burkina Faso & -9.9153 & & 0 & -13.945 & & 0 \\
\hline Benin & -8.6815 & & 1 & -7.4676 & & 1 \\
\hline Mali & -10.253 & & 0 & -8.5581 & & 1 \\
\hline Niger & -8.3761 & & 0 & -6.0275 & & 1 \\
\hline Senegal & -8.2441 & & 1 & $-10 \cdot 382$ & & 0 \\
\hline Côte d'Ivoire & -8.1660 & & 0 & -4.1312 & & 2 \\
\hline Togo & -8.6025 & & 0 & -7.4531 & & 2 \\
\hline$t-b a r$ & -8.8912 & & & -8.2806 & & \\
\hline$(1 \div \quad C V=-2.27)$ & & & & & & \\
\hline & & & & & & \\
\hline BCEAO & -9.7693 & & 0 & -6.6028 & & 1 \\
\hline
\end{tabular}

Individual $A D F$ t-statistics for ecmf ( $p^{f}(i)-p^{f}(C I V)$ ) and ecmr ( $p^{r}(i)-$ $\left.p^{r}(C I V)\right)$

( $A D F$ regressions include seasonal intercepts plus trend)

\begin{tabular}{lcccc} 
& \multicolumn{2}{c}{ ecmf } & \multicolumn{2}{c}{ ecmr } \\
Burkina Faso & $A D F t$ & lag order & $A D F t$ & lag order \\
Benin & -3.2758 & 0 & -4.2054 & 0 \\
Mali & -3.7748 & 0 & -3.2111 & 0 \\
Niger & -2.8399 & 0 & -5.3792 & 0 \\
Senegal & -3.1084 & 0 & -3.6263 & 0 \\
Togo & -2.2512 & 0 & -3.9618 & 0 \\
t-bar & -3.1127 & 0 & -4.2757 & 0 \\
(1드 $C V=-2.91)$ & -3.0605 & & -4.1099 &
\end{tabular}

Individual $A D F$ t-statistics for ( $p^{f}(i)-p^{r}$ (i))

( $A D F$ regressions include seasonal intercepts but no trend)

$\begin{array}{lcc} & A D F t & \text { lag order } \\ \text { Burkina Faso } & -2.3758 & 0 \\ \text { Benin } & -2.7272 & 0 \\ \text { Mali } & -2.1682 & 2 \\ \text { Niger } & -1.5541 & 2 \\ \text { Senegal } & -2.7111 & 0 \\ \text { Côte d'Ivoire } & -2.1599 & 1 \\ \text { Togo } & -3.0353 & 0 \\ \text { t-bar } & -2.3902 & \\ (1 \div C V=-2.27) & \end{array}$




\subsection{Time-series properties of the data}

Table 1 reports ADF unit root statistics for the series of interest. For the inflation series, we will make inferences about orders of integration on the basis of panel unit root test statistics. It is highly improbable that the food price inflation series will have different orders of integration in the different UEMOA countries; the same is true for non-food price inflation. The first part of the Table shows individual ADF t-ratios for the $\Delta p_{i t}^{f}$ and $\Delta p_{i t}^{r}$ variables, and corresponding t-bar panel unit root statistics (Im et al. 2003). The null that the series are I(1) can be rejected at the 1 per cent level in both cases. For $\Delta m_{t}$ and $\Delta r_{t}$ the univariate unit root tests also indicate rejection of the null at the 1 per cent level.

Our model also assumes that the various price series are cointegrated. We test this assumption by conducting panel unit root tests for three sets of equilibrium correction terms corresponding to those in equation (1): $\left[p_{i t-1}^{f}-p_{i t-1}^{r}\right],\left[p_{i t-1}^{f}-p_{C V V t-1}^{f}\right]$ and $\left[p_{i t-1}^{r}-p_{C I V t-1}^{r}\right]$. The bottom part of Table 1 reports the results of these tests. In all three cases the null that the series are I(1) can be rejected at the 1 per cent level, although in the case of $\left[p_{i t-1}^{f}-p_{C I V t-1}^{f}\right]$ and $\left[p_{i t-1}^{r}-p_{C I V t-1}^{r}\right]$ this is only true when the alternative allows for a deterministic linear trend. In other words, we can assume that prices across the different countries of the UEMOA are cointegrated as long as we accept that there are secular trends in the relative price series.

On the basis of the results in Table 1, the variables appearing in the model outlined in the previous section will all be treated as $\mathrm{I}(0)$ variables.

\section{The fitted model}

\subsection{Parameter estimates}

The parameters of model represented by equations (7-8) for the seven countries are estimated by FIML. (OLS is not efficient because the regression residuals are correlated with each other.) The full fitted model is reported in Table A1 in the appendix; the lag order in this model (one) is favoured by the Hannan-Quinn and Akaike information criteria. The deterministic components of the model are a seasonally varying intercept and a linear trend. Two alternative estimates are reported. The first is an unrestricted version and the second incorporates a set of parameter restrictions, some coefficients being set to zero so as to minimize the Hannan-Quinn information criterion. The response profiles discussed below are based on the restricted model, though the general stylized facts presented are also true if we use the unrestricted model.

As reported in the summary statistics Table (Table A2 in the appendix), the equilibrium correction terms are jointly significant in the unrestricted model at the 5 per cent level in all equations except those for Côte d'Ivoire. Note that in the case of Côte d'Ivoire there is a single equilibrium correction term, reflecting the assumption that Ivorian prices are not affected by prices elsewhere in the UEMOA in the long run. If any of the other pairs 
of equilibrium correction terms $\left(\left\lfloor p_{i t-1}^{f}-p_{C I V t-1}^{f}\right\rfloor,\left\lfloor p_{i t-1}^{r}-p_{C I V t-1}^{r}\right\rfloor\right)$ are included in the Ivorian equations, the coefficients on them are not significantly different from zero. Neither are they jointly significant when all are added simultaneously. In fact, the Ivorian equilibrium correction term $\left[p_{C I V t-1}^{f}-p_{C I V t-1}^{r}\right]$ is significant only at the 10 per cent level in the $\Delta p_{C I V t}^{f}$ equation, and not significant at all in the $\Delta p_{C I V t}^{r}$ equation. Nevertheless, the Hannan-Quinn criterion indicates the inclusion of the equilibrium correction term in the $\Delta p_{C I V t}^{f}$ equation, and the response profiles discussed below do incorporate internal price convergence in Côte d'Ivoire. The whole system is dynamically stable, and a temporary shock to any one variable does not cause a permanent change in any of the variables in the model.

Table A2 also reports Chow Test statistics for parameter stability. These are constructed by fitting the model to a sample that excludes the last $n$ observations, which are then used as a forecast period. The statistics reported are for $n=6$ to $n=42$ (that is, for six months to 3.5 years). 12 The forecast errors are not significant at the 5 per cent level, except for forecast periods restricted to the last year of the sample. So there is some concern that there is a structural break in the last year of the sample period. However, fitting the model to a data set ending in 2001 does not substantially alter either the parameter estimates or the response profiles discussed below.

We do not dwell in any detail on the parameter estimates in Table A1. However, a few points about the fitted model are worthy of note. First, changes in the interest rate $r_{t}$ do not have any significant effect in the Ivorian price equations, and the interest rate coefficients are set to zero in the restricted model. Because Ivorian prices are not affected by other prices in the long run, this means that permanent changes in $r_{t}$ have only a short-run effect on prices in the system. However, changes in the currency stock $m_{t}$ do have a substantial and significant impact in the Ivorian price equations, so permanent changes in $m_{t}$ do lead to permanent changes in prices across the UEMOA. Second, all the lagged inflation terms have a significant impact in at least one of the other equations, so the short-run evolution of prices is the result of a complex web of interactions between food and non-food prices in the different countries.

\subsection{The response profiles for food and non-food prices}

Figures 4-7 illustrate the response of food and non-food prices in the seven countries prices to a (permanent) unit change in the currency stock $m_{t}$ and in the interest rate $r_{t}$ over the first 12 months after the change. These charts correspond to the data recorded in Table 3, which reports the average monthly inflation rate for each price series at four, eight and 12 months after a 1 per cent change in each of the two policy instruments, with the corresponding standard deviations of inflation around this mean. 13

12 In the notation of Doornik and Hendry (2001), these are V[e] forecast error statistics that allow for parameter uncertainty.

13 That is, standard deviations of the hypothetical inflation rate, not standard errors of the inflation estimates. 
Figure 4: Reponse of $p^{f}$ to a unit increase in $m$, months 1-12

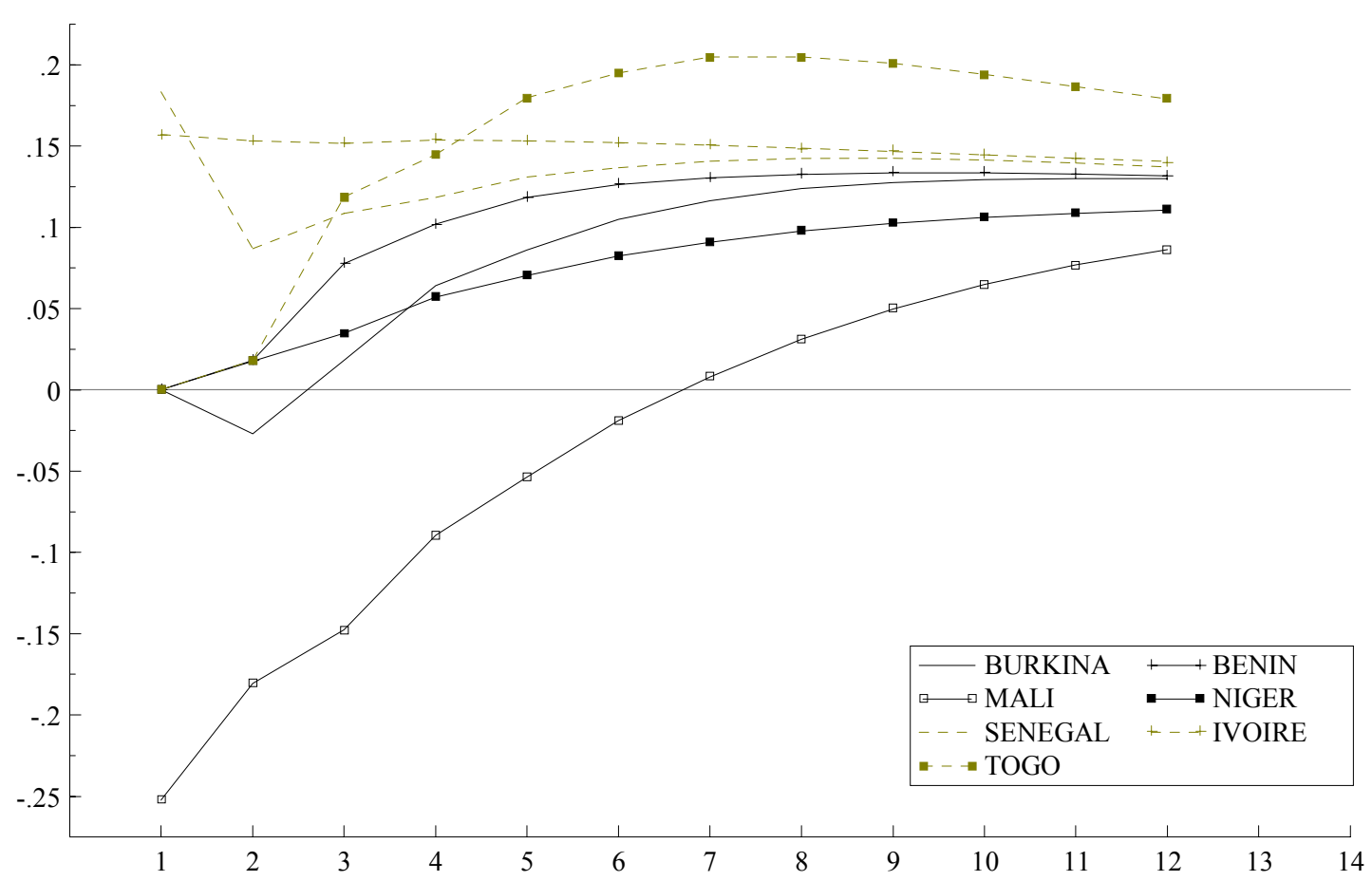

Figure 5: Reponse of $p^{r}$ to a unit increase in $m$, months $1-12$

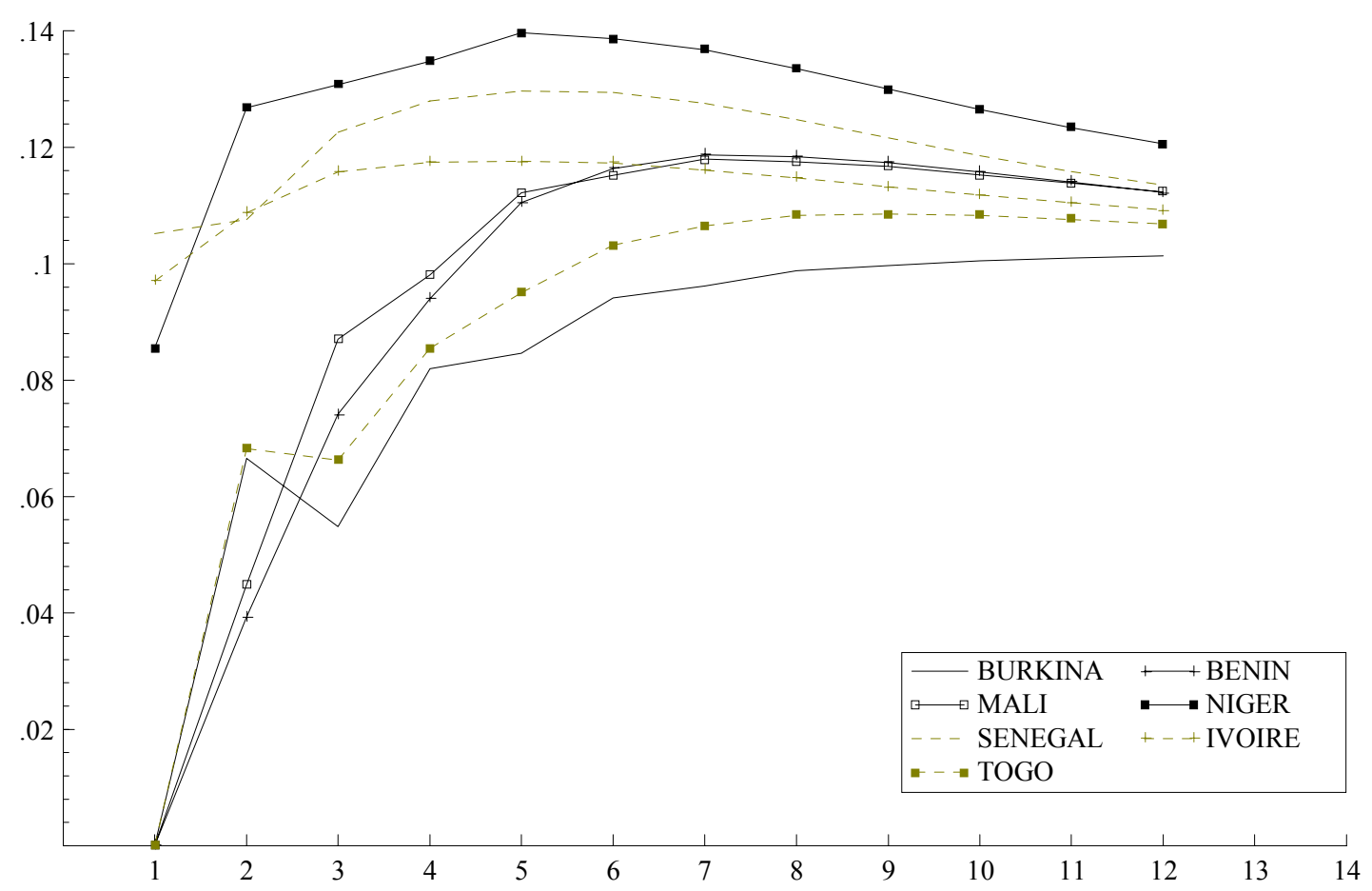


Figure 6: Reponse of $p^{f}$ to a unit decrease in $r$, months 1-12

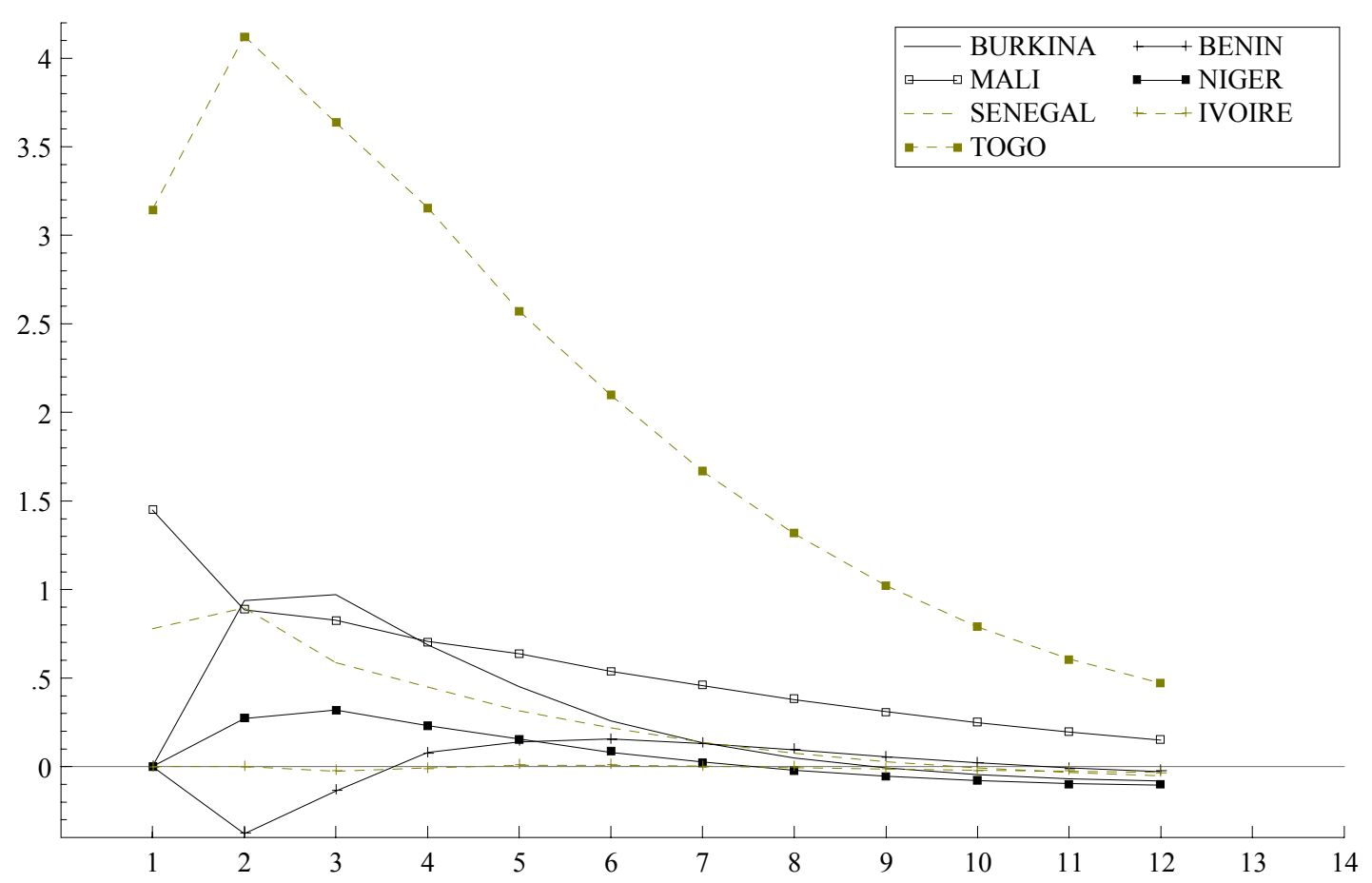

Figure 7: Reponse of $p^{r}$ to a unit decrease in $r$, months $1-12$

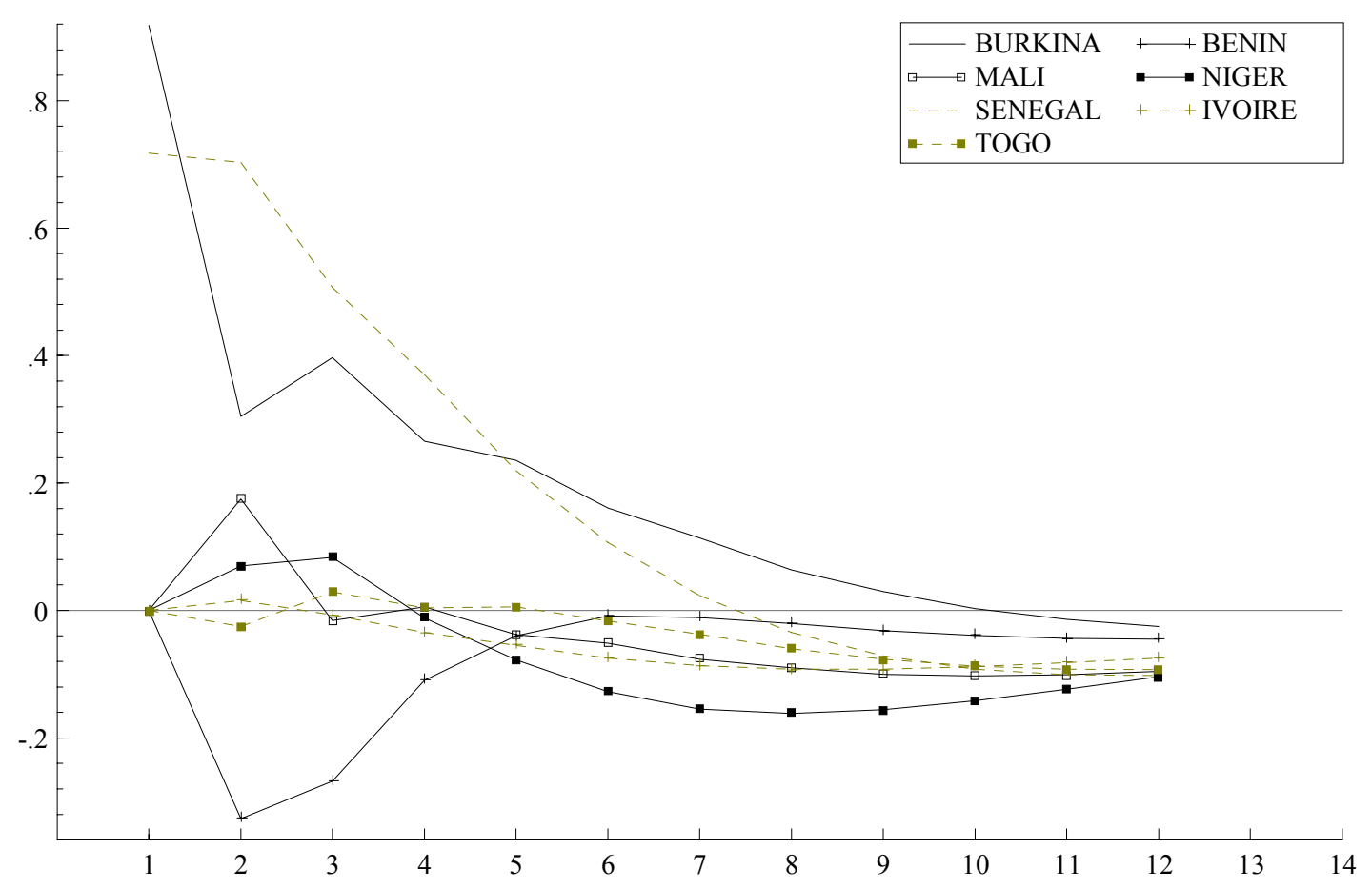


Table 2

Summary statistics for BCEAO MO growth and base interest rate

\begin{tabular}{|c|c|c|c|c|}
\hline & mean & std. dev. & minimum & maximum \\
\hline$m \quad(m c$ & $0.78 \%$ & $4.37 \%$ & $-7.74 \%$ & $15.66 \%$ \\
\hline (monthly) & $-0.08 \%$ & $0.37 \%$ & $-2.50 \%$ & $0.75 \%$ \\
\hline
\end{tabular}

Table 3

Simulated average values of monthly food / non-food price inflation in response to a 1\% increase in $m$ / a percentage point decrease in $r$, for 4, 8 and 12 months after the change (figures are in per cent)

\begin{tabular}{|c|c|c|c|c|}
\hline $\begin{array}{l}12 \text { month figures } \\
\text { Burkina Faso }\end{array}$ & $\begin{array}{l}p_{f} \text { with } r \\
-0.00667\end{array}$ & $\begin{array}{l}p_{r} \text { with } r \\
-0.00209\end{array}$ & $p_{f}$ with m & $\begin{array}{l}p_{r} \text { with } m \\
0.00845\end{array}$ \\
\hline (std. dev.) & 0.31385 & 0.33845 & 0.02022 & 0.02035 \\
\hline Benin & -0.00241 & -0.00376 & 0.01096 & 0.00935 \\
\hline (std. dev.) & 0.15379 & 0.11329 & 0.01751 & 0.01485 \\
\hline Mali & 0.01239 & -0.00796 & 0.00719 & 0.00936 \\
\hline (std. dev.) & 0.47404 & 0.07953 & 0.08382 & 0.01674 \\
\hline Niger & -0.00874 & -0.00866 & 0.00922 & 0.01005 \\
\hline (std. dev.) & 0.09569 & 0.04453 & 0.00719 & 0.02683 \\
\hline Senegal & -0.00431 & -0.00850 & 0.01143 & 0.00946 \\
\hline (std. dev.) & 0.26583 & 0.23720 & 0.06183 & 0.03059 \\
\hline Côte d'Ivoire & -0.00276 & -0.00622 & 0.01170 & 0.00911 \\
\hline (std. dev.) & 0.01157 & 0.01395 & 0.04581 & 0.02799 \\
\hline Togo & 0.03927 & -0.00772 & 0.01492 & 0.00890 \\
\hline (std. dev.) & 1.06060 & 0.02218 & 0.03040 & 0.01966 \\
\hline $\begin{array}{l}8 \text { month figures } \\
\text { Burkina Faso }\end{array}$ & $\begin{array}{c}p_{f} \text { with } r \\
0.00614\end{array}$ & $\begin{array}{c}p_{r} \text { with } r \\
0.00796\end{array}$ & $\begin{array}{c}p_{f} \text { with m } \\
0.01547\end{array}$ & $\begin{array}{c}p_{r} \text { with m } \\
0.01235\end{array}$ \\
\hline (std. dev.) & 0.39251 & 0.42381 & 0.02383 & 0.02447 \\
\hline Benin & 0.01180 & -0.00254 & 0.01656 & 0.01480 \\
\hline (std. dev.) & 0.19092 & 0.14197 & 0.01934 & 0.01565 \\
\hline Mali & 0.04736 & -0.01124 & 0.00389 & 0.01469 \\
\hline (std. dev.) & 0.59067 & 0.09941 & 0.10486 & 0.01853 \\
\hline Niger & -0.00258 & -0.02020 & 0.01222 & 0.01669 \\
\hline (std. dev.) & 0.11922 & 0.05141 & 0.00705 & 0.03131 \\
\hline Senegal & 0.00952 & -0.00429 & 0.01779 & 0.01559 \\
\hline (std. dev.) & 0.33214 & 0.29707 & 0.07660 & 0.03663 \\
\hline Côte d'Ivoire & -0.00057 & -0.01149 & 0.01858 & 0.01434 \\
\hline (std. dev.) & 0.01390 & 0.01435 & 0.05599 & 0.03372 \\
\hline Togo & 0.16432 & -0.00752 & 0.02560 & 0.01354 \\
\hline (std. dev.) & 1.30850 & 0.02741 & 0.03256 & 0.02311 \\
\hline 4 month figures & $p_{f}$ with $r$ & $p_{r}$ with $r$ & $p_{f}$ with $m$ & $p_{r}$ with $m$ \\
\hline Burkina Faso & 0.17199 & 0.06641 & 0.01603 & 0.020488 \\
\hline (std. dev.) & 0.53062 & 0.64004 & 0.03579 & 0.034752 \\
\hline Benin & 0.02021 & -0.02747 & 0.02550 & 0.023505 \\
\hline (std. dev.) & 0.28808 & 0.20990 & 0.02488 & 0.017741 \\
\hline Mali & 0.17661 & 0.00149 & -0.02238 & 0.024517 \\
\hline (std. dev.) & 0.87713 & 0.14975 & 0.15421 & 0.022423 \\
\hline Niger & 0.05771 & -0.00295 & 0.01428 & 0.033702 \\
\hline (std. dev.) & 0.15251 & 0.06865 & 0.00979 & 0.038759 \\
\hline Senegal & 0.11220 & 0.09245 & 0.02961 & 0.031990 \\
\hline (std. dev.) & 0.47789 & 0.42352 & 0.11531 & 0.049094 \\
\hline Côte d'Ivoire & -0.00196 & -0.00867 & 0.03845 & 0.029352 \\
\hline (std. dev.) & 0.01882 & 0.02026 & 0.07914 & 0.045291 \\
\hline Togo & 0.78888 & 0.00098 & 0.03620 & 0.021365 \\
\hline (std. dev.) & 1.71620 & 0.03764 & 0.04422 & 0.032684 \\
\hline
\end{tabular}


In interpreting these figures, two scaling factors need to be taken into account. First, the inflation rates are computed on a monthly basis, so a 1 per cent inflation rate corresponds to an annualized rate of a little over 12 per cent. Second, the hypothetical unit changes in the two policy variables ought to be interpreted in terms of the observed distributions of (deseasonalized) $\Delta m_{t}$ and $\Delta r_{t}$, which are reported in Table 2. The standard deviation of $\Delta m_{t}$ is about 0.04 (that is, 4 per cent), though changes in $m_{t}$ as large as 0.16 (that is, 16 per cent) are observed. For $r_{t}$ the corresponding figures are 0.004 and 0.025 (that is, 4 and 25 basis points). So, for example, a change in $m_{t}$ equal to the largest observed change in recent years ought to have an impact of about 16 times the magnitude of the standardized figures in Table 3. If the Table reports a monthly inflation rate of 0.01 per cent for a 1 per cent change in $m_{t}$, this implies an annualized inflation rate of about 2 per cent for the largest change in $m_{t}$ actually observed.

Figures 4 and 5 show the response of prices to a change in the currency stock. There is a lot more cross-country variation in the response of food prices $\left(p_{i t}^{f}\right)$ than in that of nonfood prices $\left(p_{i t}^{r}\right)$. In the case of $p_{i t}^{f}$, the response of prices on impact is insignificantly different from zero in four of the countries. But in the two largest countries, Côte d'Ivoire and Senegal, the response to a 1 per cent increase in $m_{t}$ on impact is a price increase of over 0.15 per cent. By contrast, food prices in Mali fall by around 0.25 per cent on impact. The possible reasons for the price fall are discussed in section 1 above. By month 12, prices in all countries have begun to converge on their common long-run asymptote, a price increase of around 0.1 per cent, although there is still some substantial variation between the lowest and highest food price level. In the case of $p_{i t}^{r}$, the largest effects on impact (in Côte d'Ivoire, Senegal and Togo) are only around 0.1 per cent, and in the other four countries they are insignificantly different from zero. By month 12 , there has been rather more convergence on the asymptote than in the case of $p_{i t}^{f}$.

In Table 3 these effects are quantified in more detail. Over the first four months after a hypothetical 1 per cent increase in $m_{t}$, average monthly food price inflation rates are highest in Côte d'Ivoire, Senegal and Togo. In these countries, the inflation rate is about 0.03-0.04 per cent per month. For the largest observed change in $m_{t}$ (16 per cent), this corresponds to an annualized monthly inflation rate of 6-8 per cent. At the other extreme, a unit increase in $m_{t}$ delivers an average rate of food price deflation in Mali of over 0.02 per cent per month in the first four months. Price effects in the other four countries lie in between these two extremes. If our perspective changes to the 12-month horizon these stylized differences are still present, but the magnitude of the crosscountry variation is much smaller. Average monthly inflation in Mali is now positive, as Malian prices are pulled up to the UEMOA average, and average inflation rates among the other countries are much less dispersed.

Table 3 shows that the variation in the response of non-food price to a 1 per cent increase in $m_{t}$ is smaller. Over the first four months, average monthly inflation rates vary between about 0.02 per cent (Burkina Faso) and about 0.03 per cent (Côte d'Ivoire, Senegal and Niger). If we consider a 12-month horizon, these differences have all but disappeared.

The profiles for a change in the interest rate, depicted in Figures 6 and 7, look very different from those for a change in the currency stock. There is one substantial price 
response on impact: a percentage point fall in $r_{t}$ generates an increase in Togolese food prices of over 3 per cent. There is a similar effect in Mali, but with a magnitude about half that in Togo. Otherwise, the estimated price responses are all less than 1 per cent, which is very small considering that the average change in the interest rate is only about 4 basis points. The figures show that in all countries the price response profiles decay quite quickly to zero. Table 3 reinforces this impression. Over a four-month horizon Togo stands out as the one country with a substantial monthly inflation rate $(0.79$ per cent) in response to the unit interest rate change. The effects in all other countries are very small, even at the four-month horizon. Over longer horizons the average monthly inflation rate in Togo is very much closer to the UEMOA average.

What do these figures have to say about the cross-country distribution of the costs of an increase in the stock of currency or a decrease in the interest rate? On average, the rate of growth of the currency stock is quite small, but from time to time there are substantial monetary expansions and contractions. So it makes sense to focus on the volatility of food prices that arises in response to a monetary expansion or contraction. A simple measure of volatility is the standard deviation of inflation in the different countries implicit in the price response profiles, that is, the extent of variation in inflation as prices adjust to their new mean level. Suppose that the BCEAO decides to increase (decrease) the stock of CFA currency by 10 per cent, implying a general price increase (decrease) of about 1 per cent in the long run. Such a change in $m_{t}$ is larger than the average we have observed in recent years, but smaller than the largest observed change. This policy change might be motivated by a desire to boost (reduce) aggregate demand in response to a negative (positive) macroeconomic shock or - less likely - by an increase (decrease) in borrowing by one or other of the member state governments. Table 3 implies that the cross-country asymmetries in aggregate price responses will largely be due to asymmetries in the response of food prices. At all time horizons, the largest standard deviation in monthly inflation is in Mali (about 1.5 per cent at the fourmonth horizon, for a 10 per cent change in $m_{t}$ ). But the standard deviations of prices in Côte d'Ivoire and Senegal (0.8 per cent and 1.2 per cent at the four-month horizon) are also relatively high. Given that recent average inflation rates in the UEMOA have been of Western European magnitude - that is, less than 0.5 per cent per month - these effects are substantial. By contrast, the figures for the other four countries are much smaller, because food prices there respond much more smoothly to the change in $m_{t}$. So consumers in Mali, Côte d'Ivoire and Senegal will bear the burden of sudden (and, if the change in $m_{t}$ is a shock, unpredicted) price movements.

If we consider an interest rate change, the picture is very different. Suppose that the BCEAO reduces (increases) $r_{t}$ by three quarters of a percentage point. This represents a change of about two sample standard deviations. Table 3 implies that over a four-month horizon, the standard deviation of food price inflation in Togo will be about 1.3 per cent. 14 The standard deviation of food price inflation in Mali is about half as large as this, and in Burkina Faso and Senegal about one third as large; the corresponding figures for the other countries are very much smaller. So consumers in Togo and (to a

$141.3 \% \approx(0.75) \times(1.7162 \%)$, from the last entry in the first column in Table 3 . 
lesser extent) Mali will bear the burden of sudden (and, if the change in $r_{t}$ is a shock, unpredicted) interest rate movements. 15

\subsection{The response profiles for hypothetical income groups}

We have seen that the burden of a change in $m_{t}$, in terms of inflation volatility, falls on consumers in Mali, Côte d'Ivoire and Senegal; and that the burden of a change in $r_{t}$ falls on consumers in Togo and Mali. Which consumers: the rich or the poor? Since food prices are more sensitive to changes in monetary policy instruments than non-food prices, it is likely to be the poor. Figures 8-14 and Table 4 provide evidence on the magnitude of this effect.

Each of the figures shows the response profiles of the aggregate consumer price index for three hypothetical households in a particular country, following either a unit increase in $m_{t}$ or a unit decrease in $r_{t}$. The 'middle income household' index is the Ivorian IHPC. The 'low income household' index is constructed with a weight on food prices twice that in the Ivorian IHPC. The 'high income household' index is constructed with a weight on food prices half that in the Ivorian IHPC. 16 Of course, consumption patterns between high and low-income households differ in ways other than the share of food in total expenditure, and we do not have enough degrees of freedom to fit a more disaggregated model of consumer prices. Nevertheless, the share of food in total consumption is likely to be the major difference between rich and poor households.

Figure 8: Response of hypothetical price indices for high, middle and low income groups to a unit increase in $m$ (case A) and a unit decrease in $r$ (case B), Burkina Faso
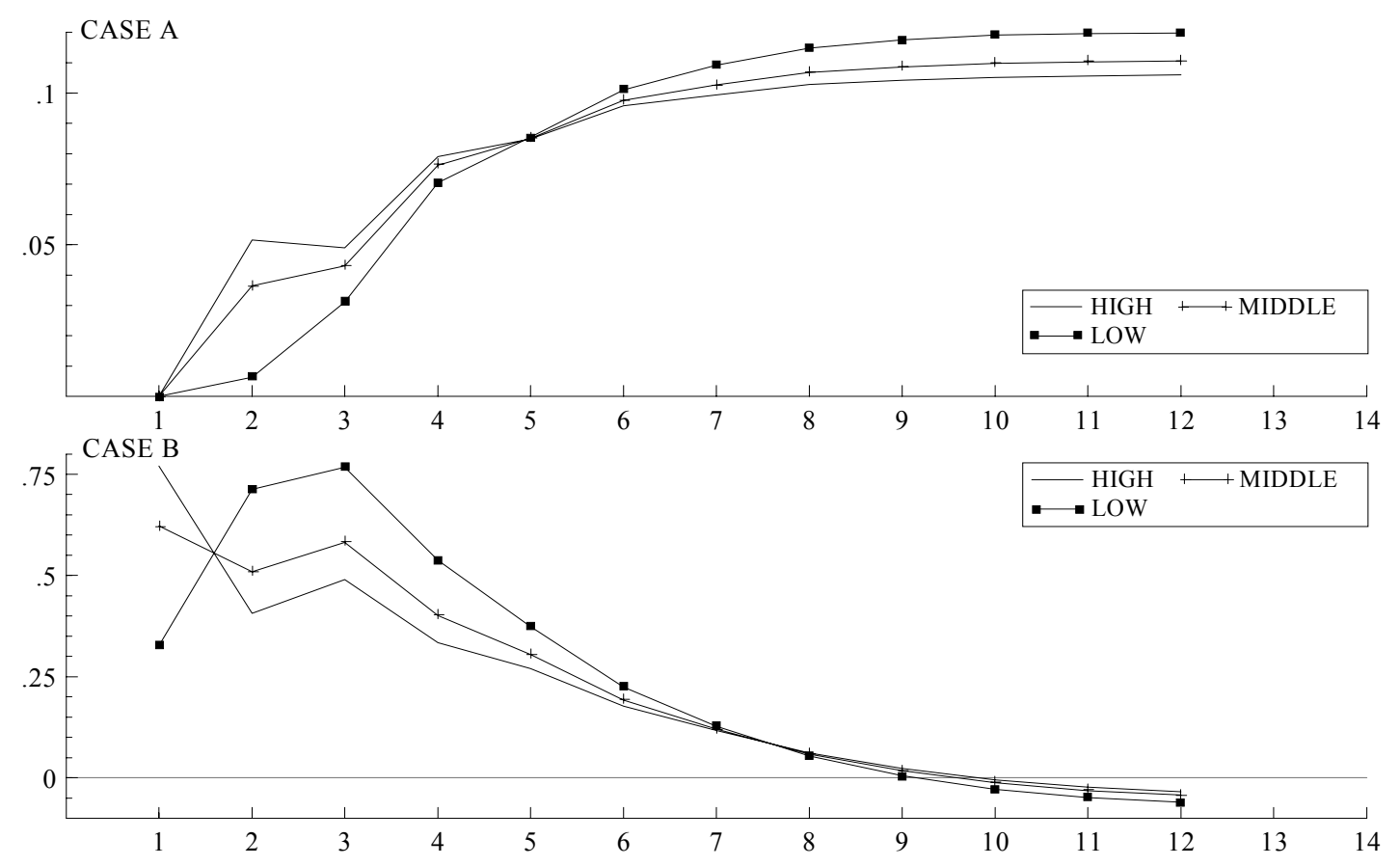

15 Admittedly, there were a couple of interest changes in excess of 10 basis points in the wake of the devaluation. But such changes are not typical of 1995 onwards.

16 The Ivorian IHPC weight on food items is 0.3221. 
Figure 9: Response of hypothetical price indices for high, middle and low income groups to a unit increase in $m$ (case A) and a unit decrease in $r$ (case B), Benin
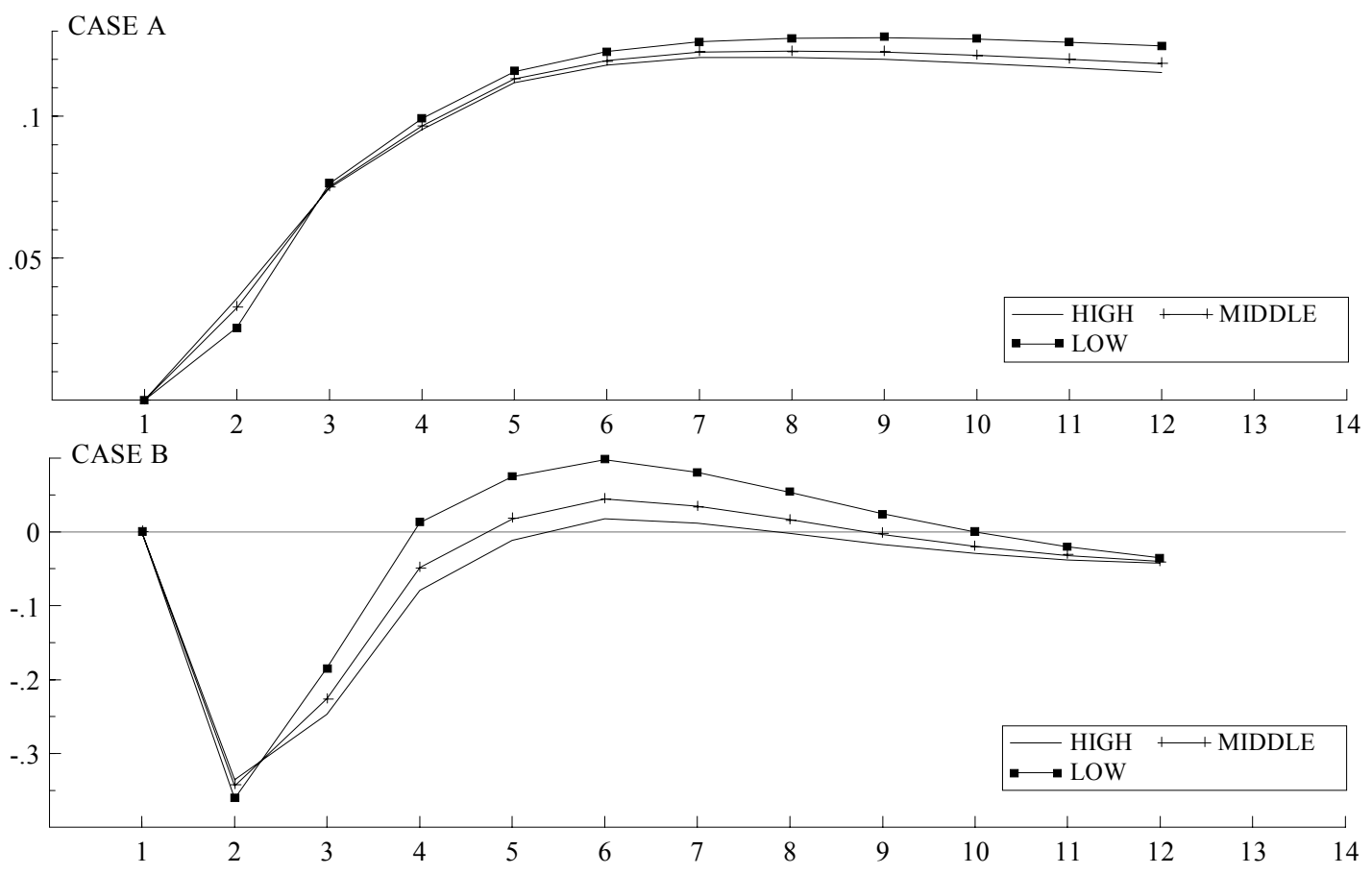

Figure 10: Response of hypothetical price indices for high, middle and low income groups to a unit increase in $m$ (case A) and a unit decrease in $r$ (case B), Mali

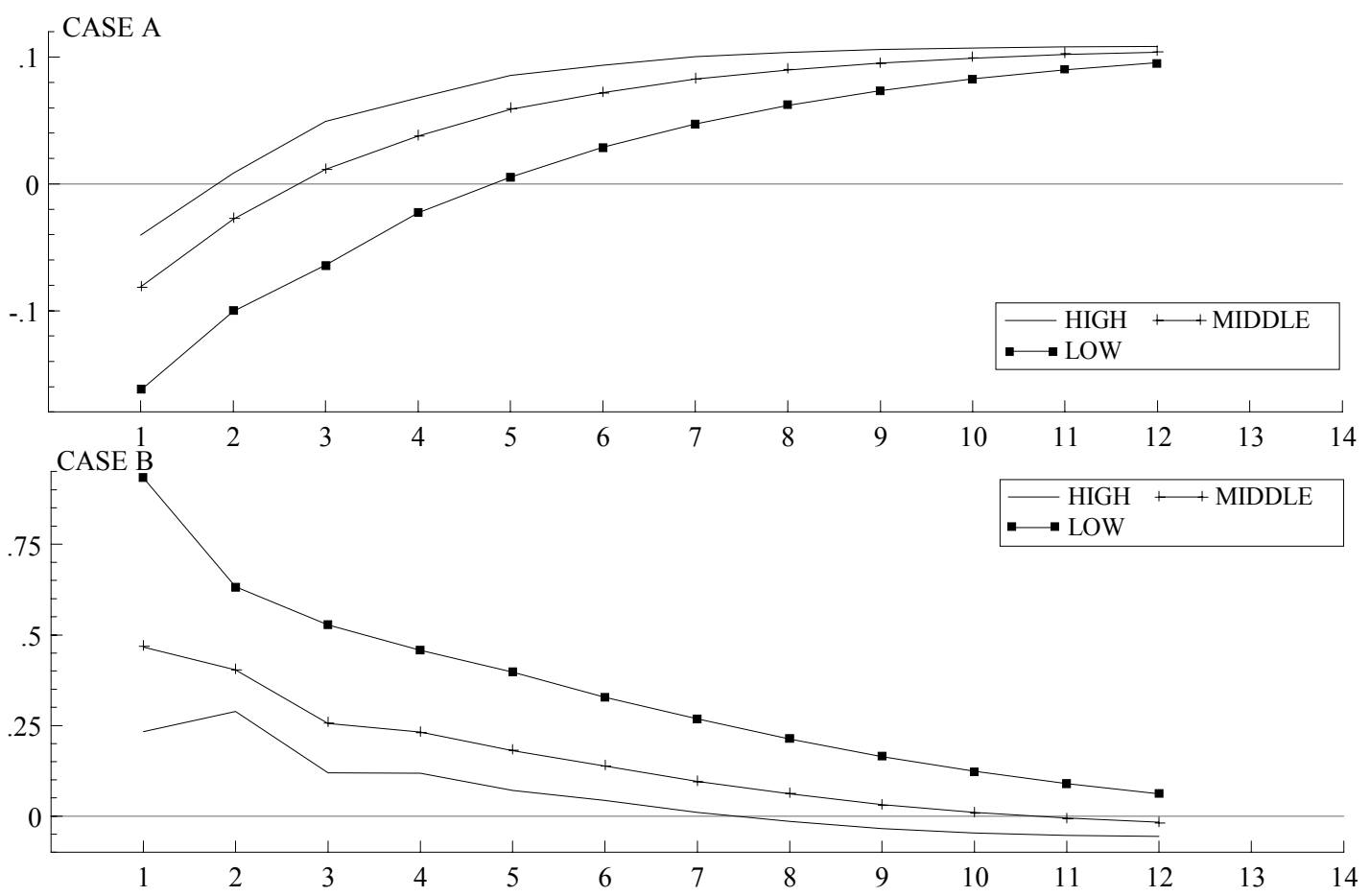


Figure 11: Response of hypothetical price indices for high, middle and low income groups to a unit increase in $m$ (case A) and a unit decrease in $r$ (case B), Niger
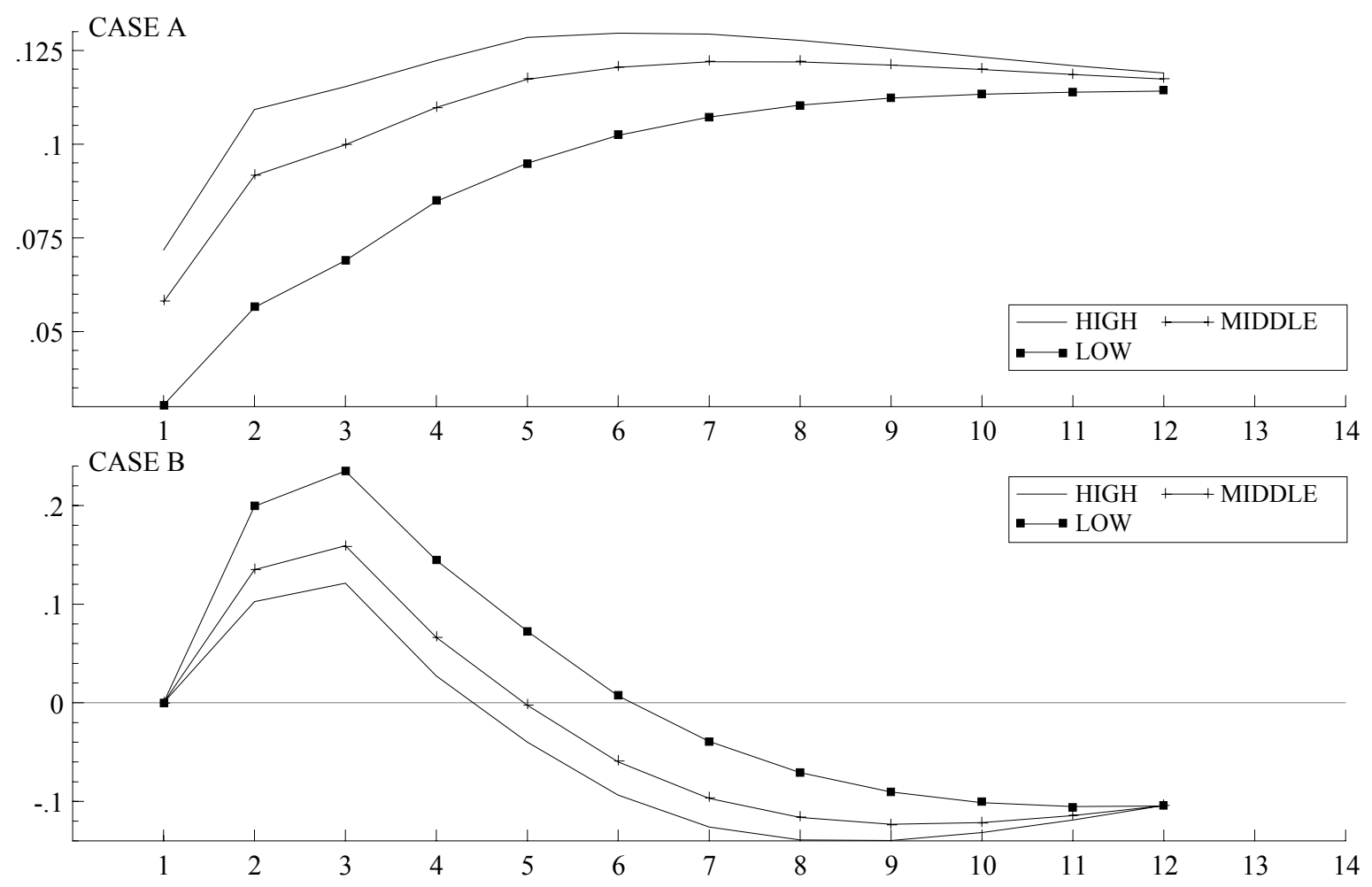

Figure 12: Response of hypothetical price indices for high, middle and low income groups to a unit increase in $m$ (case A) and a unit decrease in $r$ (case B), Senegal
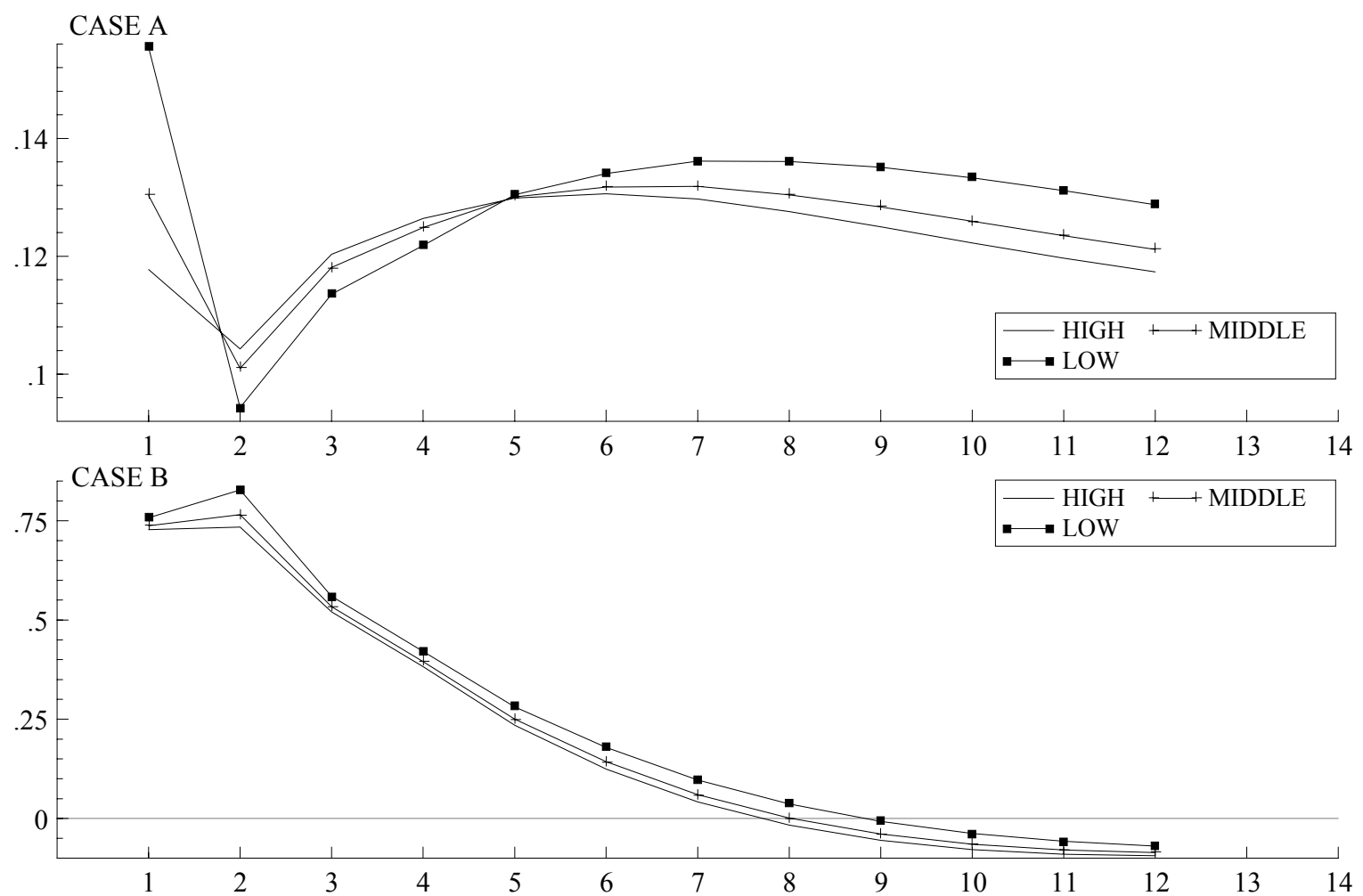
Figure 13: Response of hypothetical price indices for high, middle and low income groups to a unit increase in $m$ (case A) and a unit decrease in $r$ (case B), Côte d'Ivoire
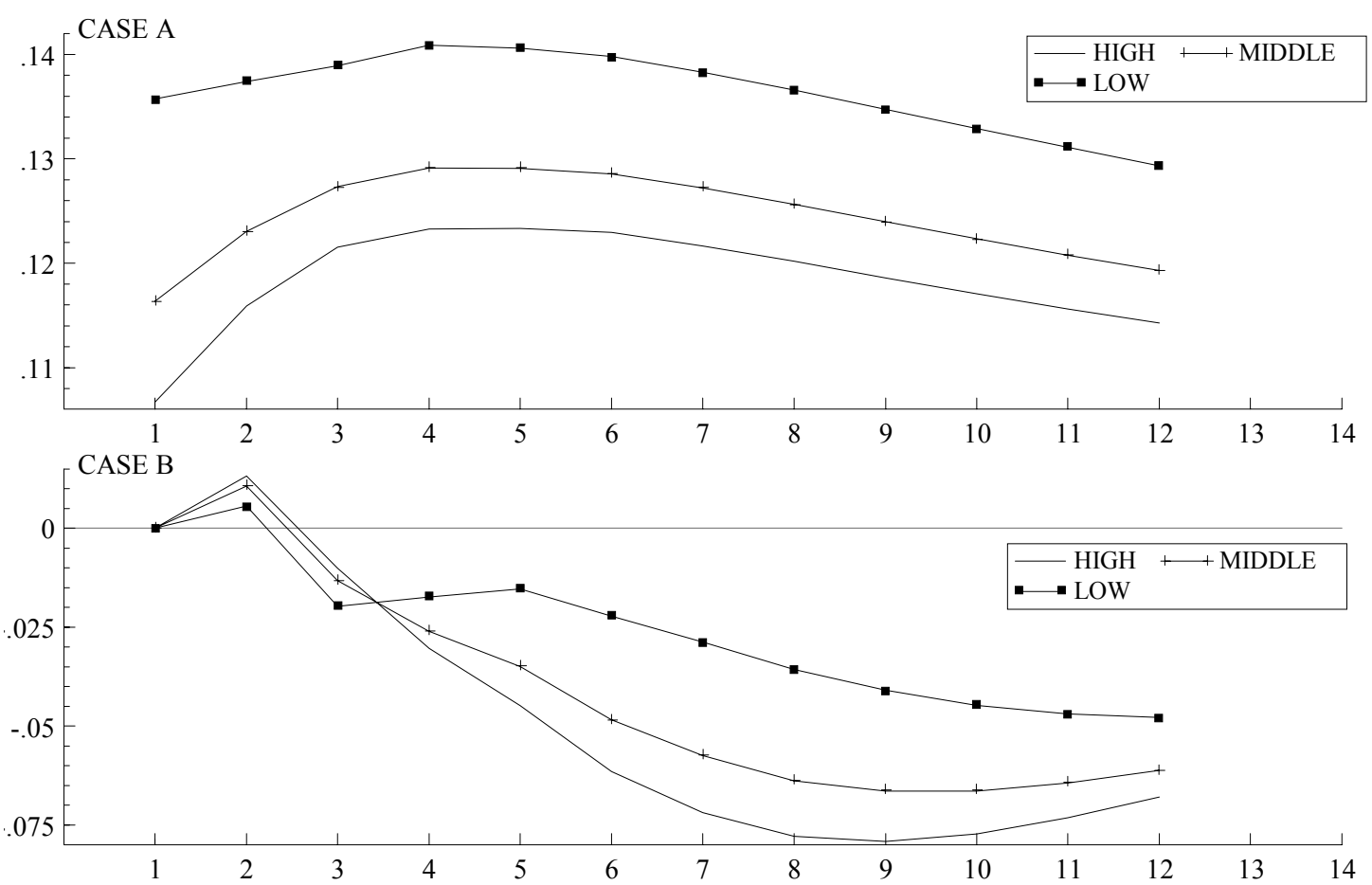

Figure 14: Response of hypothetical price indices for high, middle and low income groups to a unit increase in $m$ (case A) and a unit decrease in $r$ (case B), Togo
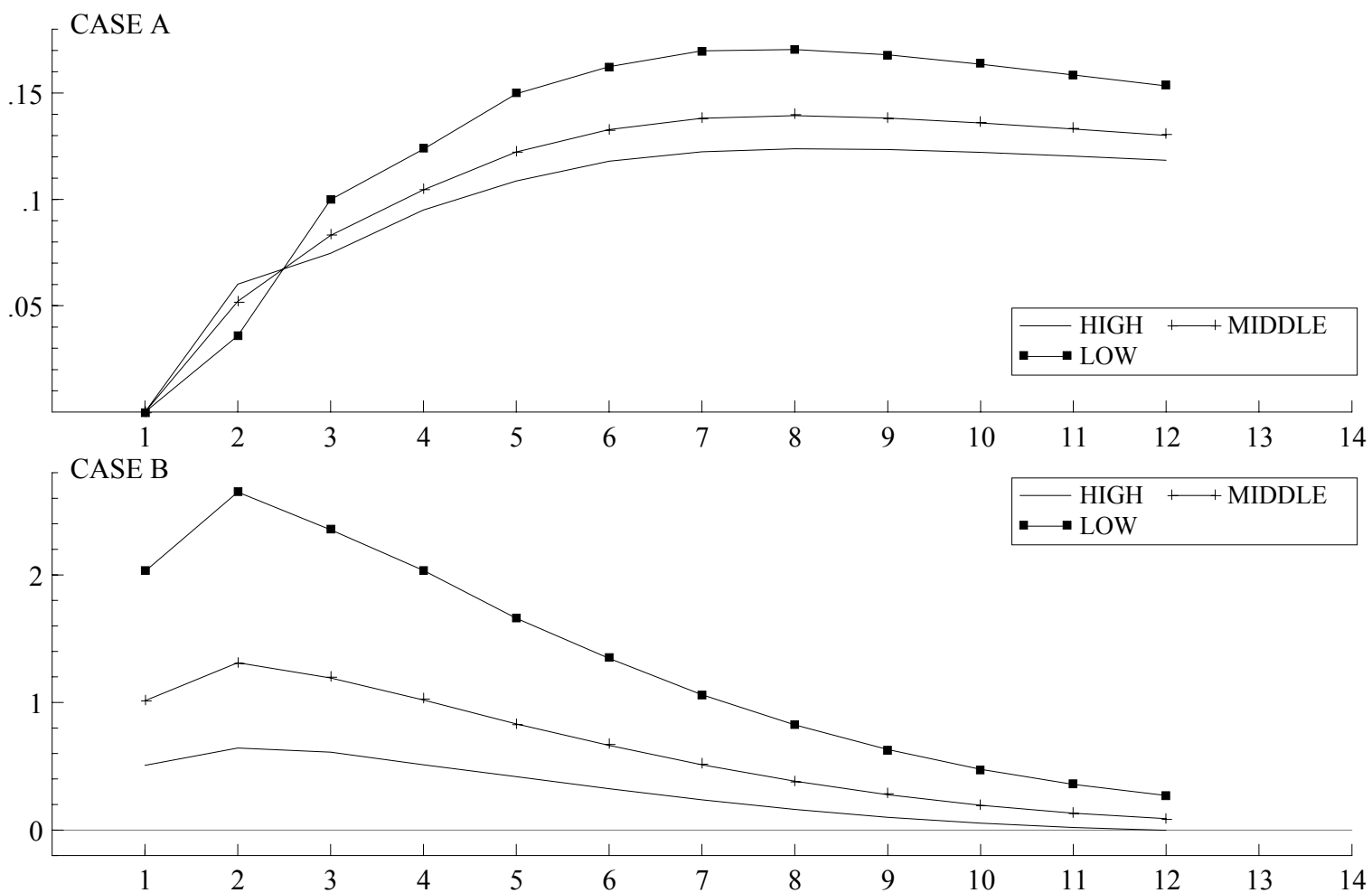
Table 4

Simulated average values of monthly consumer price inflation for three hypothetical income groups in response to a $1 \%$ increase in $\mathrm{m} / \mathrm{a}$ percentage point decrease in $r$, for 4,8 and 12 months after the change

Figures are in per cent

\begin{tabular}{|c|c|c|c|c|c|c|}
\hline $\begin{array}{l}12 \text { month figures } \\
\text { Burkina Faso }\end{array}$ & $\begin{array}{l}\text { high / m } \\
0.00883\end{array}$ & $\begin{array}{l}\text { mid / m } \\
0.00922\end{array}$ & $\begin{array}{l}\text { low } / \mathrm{m} \\
0.00999\end{array}$ & $\begin{array}{l}\text { high / r } \\
-0.00282\end{array}$ & $\begin{array}{l}\operatorname{mid} / r \\
-0.00356\end{array}$ & $\begin{array}{l}\text { low } / r \\
-0.00504\end{array}$ \\
\hline (std. & 0.01600 & 0.01257 & 0.01198 & 0.26623 & 0.20728 & 0.18572 \\
\hline Benin & 0.00961 & 0.00987 & 0.01039 & -0.00354 & -0.00333 & -0.00289 \\
\hline (std. dev.) & 0.01488 & 0.01507 & 0.01593 & 0.11847 & 0.12428 & 0.13743 \\
\hline Mali & 0.00901 & 0.00866 & 0.00796 & -0.00468 & -0.00140 & 0.00515 \\
\hline (std. dev.) & 0.02244 & 0.03253 & 0.05623 & 0.09111 & 0.15174 & 0.30117 \\
\hline Niger & 0.00992 & 0.00978 & 0.00951 & -0.00867 & -0.00869 & -0.00871 \\
\hline (std. dev.) & 0.02240 & 0.01806 & 0.01010 & 0.05031 & 0.05756 & 0.07466 \\
\hline Senegal & 0.00978 & 0.01010 & 0.01073 & -0.00783 & -0.00715 & -0.00580 \\
\hline (std. dev.) & 0.03469 & 0.03933 & 0.04961 & 0.24115 & 0.24537 & 0.25458 \\
\hline Côte d'Ivoire & 0.00952 & 0.00994 & 0.01078 & -0.00566 & -0.00510 & -0.00399 \\
\hline (std. dev.) & 0.03079 & 0.03362 & 0.03938 & 0.01138 & 0.00925 & 0.00784 \\
\hline Togo & 0.00987 & 0.01084 & 0.01278 & -0.00015 & 0.00742 & 0.02255 \\
\hline (std. dev.) & 0.01752 & 0.01707 & 0.02124 & 0.17173 & 0.34192 & 0.68327 \\
\hline 8 month figures & high / $m$ & mid / m & low $/ \mathrm{m}$ & high / $r$ & mid / $r$ & low / $r$ \\
\hline Burkina Faso & 0.01285 & 0.01336 & 0.01436 & 0.00767 & 0.00737 & 0.00679 \\
\hline (std. dev.) & 0.01862 & 0.01376 & 0.01263 & 0.33308 & 0.25890 & 0.23155 \\
\hline Benin & 0.01508 & 0.01536 & 0.01593 & -0.00023 & 0.00208 & 0.00670 \\
\hline (std. dev.) & 0.01566 & 0.01592 & 0.01713 & 0.14836 & 0.15544 & 0.17131 \\
\hline Mali & 0.01295 & 0.01121 & 0.00773 & -0.00181 & 0.00764 & 0.02651 \\
\hline (std. dev.) & 0.02716 & 0.04049 & 0.07046 & 0.11399 & 0.18942 & 0.37542 \\
\hline Niger & 0.01597 & 0.01525 & 0.01381 & -0.01737 & -0.01453 & -0.00885 \\
\hline (std. dev.) & 0.02575 & 0.02025 & 0.00985 & 0.06081 & 0.07117 & 0.09342 \\
\hline Senegal & 0.01595 & 0.01630 & 0.01701 & -0.00207 & 0.00017 & 0.00461 \\
\hline (std. dev.) & 0.04196 & 0.04795 & 0.06109 & 0.30195 & 0.30714 & 0.31842 \\
\hline Côte d'Ivoire & 0.01502 & 0.01571 & 0.01707 & -0.00973 & -0.00797 & -0.00446 \\
\hline (std. dev.) & 0.03722 & 0.04078 & 0.04796 & 0.01196 & 0.01017 & 0.00972 \\
\hline Togo & 0.01548 & 0.01742 & 0.02131 & 0.02015 & 0.04783 & 0.10318 \\
\hline (std. dev.) & 0.01935 & 0.01758 & 0.02142 & 0.21168 & 0.42168 & 0.84287 \\
\hline $\begin{array}{l}4 \text { month figures } \\
\text { Burkina Faso }\end{array}$ & $\begin{array}{c}\text { high / m } \\
0.01977\end{array}$ & $\begin{array}{l}\text { mid / m } \\
0.01905\end{array}$ & $\begin{array}{l}\text { Iow / } \mathrm{m} \\
0.01762\end{array}$ & $\begin{array}{r}\text { high / r } \\
0.08341\end{array}$ & $\begin{array}{l}\operatorname{mid} / r \\
0.10042\end{array}$ & $\begin{array}{l}\text { low } / r \\
0.13443\end{array}$ \\
\hline (std. dev.) & 0.02585 & 0.01845 & 0.01788 & 0.49323 & 0.36440 & 0.28252 \\
\hline Benin & 0.02383 & 0.02415 & 0.02479 & -0.01979 & -0.01211 & 0.00325 \\
\hline (std. dev.) & 0.01778 & 0.01832 & 0.02073 & 0.22122 & 0.23315 & 0.25843 \\
\hline Mali & 0.01697 & 0.00941 & -0.00569 & 0.02969 & 0.05790 & 0.11430 \\
\hline (std. dev.) & 0.04051 & 0.06150 & 0.10521 & 0.16603 & 0.27737 & 0.55522 \\
\hline Niger & 0.03057 & 0.02745 & 0.02119 & 0.00682 & 0.01659 & 0.03613 \\
\hline (std. dev.) & 0.03109 & 0.02343 & 0.00843 & 0.08064 & 0.09356 & 0.12096 \\
\hline Senegal & 0.03161 & 0.03122 & 0.03045 & 0.09563 & 0.09881 & 0.10517 \\
\hline (std. dev.) & 0.05873 & 0.06901 & 0.09062 & 0.43106 & 0.43911 & 0.45660 \\
\hline Côte d'Ivoire & 0.03082 & 0.03228 & 0.03521 & -0.00759 & -0.00651 & -0.00435 \\
\hline (std. dev.) & 0.05067 & 0.05609 & 0.06701 & 0.01729 & 0.01506 & 0.01416 \\
\hline Togo & 0.02375 & 0.02614 & 0.03092 & 0.12783 & 0.25476 & 0.50854 \\
\hline (std. dev.) & 0.02574 & 0.02161 & 0.02662 & 0.27122 & 0.54783 & 1.10280 \\
\hline
\end{tabular}


The figures show that in three countries - Benin, Burkina Faso and Togo - the three response profiles for a change in $m_{t}$ are virtually identical. In these countries, food and non-food prices respond in a similar way to the initial change in $m_{t}$. In Senegal the same is true from the second month onwards, but inflation is much higher for the low-income group in the first month after the new currency creation. In Côte d'Ivoire, the initial upward jump in the price index for low-income households is also much larger than for high-income households, and moreover the gap between the price indices persists for some time. (Price convergence is relatively slow in Côte d'Ivoire.) In Mali, there is virtually no initial jump in the high-income price index, because the increase in nonfood prices is offset by Mali's idiosyncratic decrease in food prices. But for low-income households, who spend a larger fraction of their income on food, there is a substantial drop in food prices after the increase in $m_{t}$, followed by a steady increase as food prices converge on non-food prices. So the price index for low-income households is much more volatile. In Niger, prices are somewhat higher for the high-income group in the 12 months following the increase in $m_{t}$, although the initial price increase is relatively small, and for all income groups the transition to the steady state is relatively smooth. This implies a relatively low inflation variance for all income groups.

Table 4 indicates the implications of these responses for the average inflation rate and the standard deviation of inflation in the 12 months following a 1 per cent change in $m_{t}$. The Table implies that groups experiencing the most inflation volatility are low-income households in Mali and Senegal. A 10 per cent change in the currency stock leads to a standard deviation of inflation of 1 per cent over the next four months for the poor in Mali, and of 0.9 per cent for the poor in Senegal. Other groups experiencing relatively high inflation volatility are middle-income households in Mali and Senegal and lowincome households in Côte d'Ivoire (all with a four-month standard deviation of over 0.6 per cent). There is also substantial volatility for high-income households in Mali and Senegal, and for middle and high-income households in Côte d'Ivoire.

The response profiles for changes in the interest rate are rather different. Only in Togo, and to a lesser extent Mali, Burkina Faso and Senegal, are there any quantitatively substantial effects. In all cases the rise in prices following a fall in the interest rate is larger for low-income households, although in Burkina Faso and Senegal this difference is negligibly small. Table 4 implies that a change in $r_{t}$ equal to three quarters of a percentage point will lead to a standard deviation of inflation in the following four months equal to 0.8 per cent for low-income households in Togo. 17 The corresponding standard deviations for low-income households in Mali, and for middle-income households in Togo, are about half this. In Burkina Faso and Senegal, all income groups experience a magnitude of inflation volatility that is marginally smaller again.

So, in general, monthly movements in either one of the monetary policy instruments can be expected to generate more price volatility for the poor than for the rich. But the volatility effects are concentrated in a limited number of countries: Mali, Senegal and Côte d'Ivoire for changes in $m_{t}$; Mali, Senegal and Togo for changes in $r_{t}$.

$170.8 \% \approx(0.75) \times(1.1028 \%)$, from the last entry in the last column in Table 4. 


\subsection{A note on orders of magnitude}

How important are the magnitudes indicated above? If one just considers a single unanticipated change in a monetary policy instrument, then the conclusion will be that there is a small - but not entirely negligible - impact on welfare. For example, a 10 per cent contraction of the stock of currency causes the aggregate price index for our hypothetical low-income Malian household to rise by about 1.4 per cent in the first month, a figure that has declined to 0.2 per cent by the fourth month. If all of this price increase is met by a reduction in food consumption (because household income and other expenditure commitments, such as rent, are fixed in the short term), and if each household member eats one meal per day, then the consumption foregone is equal to about 1.5 meals per person.

However, if one considers the persistent volatility in inflation that is likely to result from frequent changes in monetary policy instruments (and remember that the standard deviation of deseasonalized monthly $\Delta m_{t}$ is over 4 per cent), the figures calculated above are substantial relative to the inflation targets used by central banks in OECD countries. For example, the Bank of England aims to keep aggregate annualized inflation within one percentage point either side of a target rate. We have seen that a 10 per cent change in $m_{t}$ results in an immediate monthly change in food prices in Mali of 2.5 per cent (Figure 4), and a corresponding change in aggregate prices for low-income households of 1.4 per cent (Figure 10).

\section{Summary and conclusion}

We have fitted a model of urban food and non-food prices to monthly time-series data for different countries in the West African Economic and Monetary Union, in order to examine the asymmetries of price response that arise after a change in a monetary policy instrument. Although the countries share a common currency and a single central bank (the BCEAO), and although prices across the monetary union are cointegrated, there are some significant short-run asymmetries, both across countries and across commodities. We have explored the consequences of these asymmetries for different income groups in different member states. Households in a subset of the countries especially poor households - bear the brunt of the price volatility that occurs in the wake of a change in the value of one of the instruments.

This does not mean that the BCEAO should abandon monetary policy. The policy instruments at its disposal are a potentially valuable set of tools to combat the price uncertainty that arises from exogenous shocks and increases the vulnerability of the poor. However, policymakers do need to be aware of the distributional asymmetries that arise as a consequence of monetary policy interventions. There may be a need for targeted measures (for example, food subsidies), to reduce the price volatility that faces certain income groups in certain countries following a large monetary adjustment.

We should stress that the results here relate to urban prices. High-frequency time-series data for rural areas are not available. The heterogeneity we observe between cities and between income groups suggests that there might well be some heterogeneity between urban and rural areas. This is an important topic for future research. 


\section{References}

Appleyard, R. (1999). Emigration Dynamics in Developing Countries. Vol. 1. SubSaharan Africa. Bookpoint, Abingdon.

Azam, J.-P. (2003). 'Poverty and Growth in the WAEMU After the 1994 Devaluation'. Mimeo. UNU-WIDER, Helsinki.

Cardoso, E. (1992). 'Inflation and Poverty'. Working Paper 4006. NBER, Washington, DC.

Cobham, D. (2001). 'Capital Account Liberalization and Poverty'. Working Paper 70. Queen Elizabeth House, University of Oxford.

Doornik, J. and D. Hendry (2001). Empirical Econometric Modelling Using PcGive (3rd edition). Timberlake Consultants Press, London.

Easterly, W. and S. Fischer (2000). 'Inflation and the Poor', World Bank (Country Economics Department) Working Paper 2335. Washington, DC.

Fielding, D. (1999). 'How Does a Central Bank React to Changes in Government Borrowing?'. Journal of Development Economics, 59: 531-52.

Ganuza, E. and L. Taylor (1998). 'Macroeconomic Policy, Poverty, and Equality in Latin America and the Caribbean'. Working Paper 6. CEPA, New School for Social Research, New York, NY.

Im, K., M. Pesaran and Y. Shin (2003). 'Testing for Unit Roots in Heterogeneous Panels'. Journal of Econometrics, 115: 53-74.

Nuven, D. (1994). 'Linkages in the Price Level and Inflation Rate Between CFA Franc Zone Countries and France'. Working Paper WPS/94/93-EA. IMF, Washington, DC.

Pesaran, M., Y. Shin and R. Smith (2001). 'Bounds Testing Approaches to the Analysis of Levels Relationships'. Journal of Applied Econometrics, 16: 289-326.

Romer, C. and D. Romer (1998). 'Monetary Policy and the Well-being of the Poor', NBER Working Paper 6793. Washington, DC.

Shortland, A. and D. Stasavage (2003a). 'Country-level Monetary Policy in the CFA Zone'. Mimeo. UNU-WIDER, Helsinki.

Shortland, A. and D. Stasavage (2003b). 'Monetary Policy in the Franc Zone: Estimating Interest Rate Rules for the BCEAO'. Mimeo. UNU-WIDER, Helsinki.

Sugimoto, K. (2001). 'One Money or Two Monies? Monetary Policy in the CFA Franc Zone, 1968-93'. Journal of African Economies, 10: 64-91. 


\section{Table A1: The fitted price equations}

All equations are estimated by FIML and include a linear trend \& seasonal intercept. In each Table

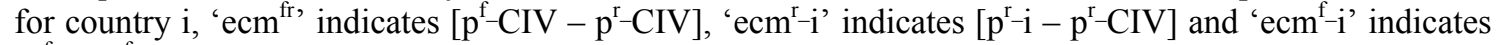
$\left[\mathrm{p}^{\mathrm{f}}-\mathrm{i}-\mathrm{p}^{\mathrm{f}}-\mathrm{CIV}\right]$

\begin{tabular}{|c|c|c|c|c|c|c|}
\hline$\Delta \mathrm{p}^{\mathrm{f}}-\mathrm{bfa}$ & \multicolumn{3}{|c|}{ Unrestricted } & \multicolumn{3}{|c|}{ Restricted } \\
\hline Variable & coeff. & s.e. & h.c.s.e. & coeff. & s.e. & h.c.s.e. \\
\hline$\Delta \mathrm{p}^{\mathrm{f}}-\mathrm{b} f \mathrm{a}_{-1}$ & +0.00841 & 0.12834 & 0.12812 & & & \\
\hline$\Delta \mathrm{p}^{\mathrm{r}}-\mathrm{b} f \mathrm{a}_{-1}$ & -0.01933 & 0.22694 & 0.25329 & & & \\
\hline$\Delta \mathrm{p}^{\mathrm{f}}$-ben & -0.01601 & 0.10579 & 0.09795 & & & \\
\hline$\Delta \mathrm{p}^{\mathrm{r}}-$ ben $_{-1}$ & +0.06967 & 0.20718 & 0.20213 & & & \\
\hline$\Delta \mathrm{p}^{\mathrm{f}}-\mathrm{mal}_{-1}$ & -0.06856 & 0.12980 & 0.14551 & & & \\
\hline$\Delta \mathrm{p}^{\mathrm{r}}-\mathrm{mal}_{-1}$ & -0.02754 & 0.15498 & 0.14222 & & & \\
\hline$\Delta \mathrm{p}^{\mathrm{f}}-$ ner $_{-1}$ & +0.13809 & 0.17413 & 0.17693 & & & \\
\hline$\Delta \mathrm{p}^{\mathrm{r}}-$ ner $_{-1}$ & -0.05404 & 0.31359 & 0.27549 & & & \\
\hline$\Delta \mathrm{p}^{\mathrm{f}}-\mathrm{sen}_{-1}$ & +0.10247 & 0.15563 & 0.15845 & & & \\
\hline$\Delta \mathrm{p}^{\mathrm{r}}-\mathrm{sen}_{-1}$ & -0.59765 & 0.46649 & 0.41548 & & & \\
\hline$\Delta \mathrm{p}^{\mathrm{f}}-\mathrm{Ci} \mathrm{v}_{-1}$ & -0.36272 & 0.21943 & 0.16782 & -0.30150 & 0.13169 & 0.10490 \\
\hline$\Delta \mathrm{p}^{\mathrm{r}}-\mathrm{Civ}_{-1}$ & -0.15183 & 0.46966 & 0.43223 & & & \\
\hline$\Delta \mathrm{p}^{\mathrm{f}}-\operatorname{tog}_{-1}$ & +0.24823 & 0.10793 & 0.10244 & +0.22930 & 0.06597 & 0.07011 \\
\hline$\Delta \mathrm{p}^{\mathrm{r}}-\operatorname{tog}_{-1}$ & -0.08399 & 0.21493 & 0.18925 & & & \\
\hline$\Delta \mathrm{m}_{-1}$ & -0.16035 & 0.14961 & 0.12376 & & & \\
\hline$\Delta i_{-1}$ & -0.42036 & 0.84899 & 0.81942 & & & \\
\hline $\mathrm{ecm}^{\mathrm{fr}}-1$ & -0.00299 & 0.05799 & 0.06658 & & & \\
\hline $\mathrm{ecm}^{\mathrm{r}}-\mathrm{b} f \mathrm{a}_{-1}$ & +0.32604 & 0.16327 & 0.15081 & +0.23653 & 0.11756 & 0.12244 \\
\hline$e c m^{\mathrm{f}}-\mathrm{b} f \mathrm{a}_{-1}$ & -0.28445 & 0.05890 & 0.05823 & -0.27612 & 0.050801 & 0.051523 \\
\hline$\sigma$ & +0.02310 & & & +0.02187 & & \\
\hline$\Delta \mathrm{p}^{\mathrm{r}}-\mathrm{bfa}$ & \multicolumn{3}{|c|}{ Unrestricted } & \multicolumn{3}{|c|}{ Restricted } \\
\hline Variable & coeff. & s.e. & h.c.s.e. & coeff. & s.e. & h.c.s.e. \\
\hline$\Delta \mathrm{p}^{\mathrm{f}}-\mathrm{bf} \mathrm{a}_{-1}$ & +0.02736 & 0.05823 & 0.057433 & & & \\
\hline$\Delta \mathrm{p}^{\mathrm{r}}-\mathrm{bf} \mathrm{a}_{-1}$ & -0.12627 & 0.10321 & 0.13495 & -0.17316 & 0.07688 & 0.09615 \\
\hline$\Delta \mathrm{p}^{\mathrm{f}}-\mathrm{ben}_{-1}$ & -0.04982 & 0.04801 & 0.047705 & & & \\
\hline$\Delta \mathrm{p}^{\mathrm{r}}-$-ben $_{-1}$ & +0.30286 & 0.09408 & 0.081759 & +0.26017 & 0.06602 & 0.05833 \\
\hline$\Delta \mathrm{p}^{\mathrm{f}}-\mathrm{mal}_{-1}$ & -0.19766 & 0.05891 & 0.068736 & -0.19469 & 0.04481 & 0.05627 \\
\hline$\Delta \mathrm{p}^{\mathrm{r}}-\mathrm{mal}_{-1}$ & +0.06063 & 0.07034 & 0.068189 & & & \\
\hline$\Delta \mathrm{p}^{\mathrm{f}}-\mathrm{ner}_{-1}$ & +0.11619 & 0.07904 & 0.085541 & 0.11389 & 0.05708 & 0.06960 \\
\hline$\Delta \mathrm{p}^{\mathrm{r}}-$ ner $_{-1}$ & -0.02796 & 0.14238 & 0.14903 & & & \\
\hline$\Delta \mathrm{p}^{\mathrm{f}}-$ sen $_{-1}$ & +0.09917 & 0.07064 & 0.067634 & 0.11864 & 0.04823 & 0.05079 \\
\hline$\Delta \mathrm{p}^{\mathrm{r}}-\mathrm{sen}_{-1}$ & +0.07533 & 0.21164 & 0.19264 & & & \\
\hline$\Delta \mathrm{p}^{\mathrm{f}}{ }^{-} \mathrm{Ci} \mathrm{v}_{-1}$ & -0.22421 & 0.09949 & 0.079048 & -0.20604 & 0.06010 & 0.04912 \\
\hline$\Delta \mathrm{p}^{\mathrm{r}}-\mathrm{Ci} \mathrm{v}_{-1}$ & -0.00412 & 0.21316 & 0.20089 & & & \\
\hline$\Delta \mathrm{p}^{\mathrm{f}}-\operatorname{tog}_{-1}$ & +0.02001 & 0.04903 & 0.036363 & & & \\
\hline$\Delta \mathrm{p}^{\mathrm{r}}-\operatorname{tog}_{-1}$ & -0.04051 & 0.09756 & 0.074093 & & & \\
\hline$\Delta \mathrm{m}_{-1}$ & +0.07261 & 0.06799 & 0.059137 & & & \\
\hline$\Delta r_{-1}$ & -0.88845 & 0.38566 & 0.54319 & -0.91867 & +0.26666 & 0.27437 \\
\hline $\mathrm{ecm}^{\mathrm{fr}}-1$ & -0.00213 & 0.02634 & 0.024636 & & & \\
\hline $\mathrm{ecm}^{\mathrm{r}}-\mathrm{b} f \mathrm{a}_{-1}$ & -0.33174 & 0.07515 & 0.083387 & -0.28885 & 0.05737 & 0.08089 \\
\hline$e^{f}{ }^{f}-b f a_{-1}$ & +0.00729 & 0.02615 & 0.026235 & & & \\
\hline$\sigma$ & +0.01049 & & & +0.0097 & & \\
\hline
\end{tabular}


Table A1 (Continued)

\begin{tabular}{|c|c|c|c|c|c|c|}
\hline$\Delta \mathrm{p}^{\mathrm{f}}$-ben & \multicolumn{3}{|c|}{ Unrestricted } & \multicolumn{3}{|c|}{ Restricted } \\
\hline Variable & Coeff. & s.e. & h.c.s.e. & coeff. & s.e. & h.c.s.e. \\
\hline$\Delta \mathrm{p}^{\mathrm{f}}-\mathrm{bf} \mathrm{a}_{-1}$ & +0.05399 & 0.15579 & 0.13810 & & & \\
\hline$\Delta \mathrm{p}^{\mathrm{r}}-\mathrm{bfa} \mathrm{a}_{-1}$ & -0.17330 & 0.26161 & 0.22756 & & & \\
\hline$\Delta \mathrm{p}^{\mathrm{f}}$-ben & -0.03202 & 0.13670 & 0.11126 & & & \\
\hline$\Delta \mathrm{p}^{\mathrm{r}}$-ben & +0.09123 & 0.25827 & 0.22077 & & & \\
\hline$\Delta \mathrm{p}^{\mathrm{f}}-\mathrm{mal}_{-1}$ & -0.08132 & 0.16194 & 0.16005 & & & \\
\hline$\Delta \mathrm{p}^{\mathrm{r}}-\mathrm{mal}_{-1}$ & -0.11446 & 0.19184 & 0.18853 & & & \\
\hline$\Delta \mathrm{p}^{\mathrm{f}}-\mathrm{ner}_{-1}$ & +0.17437 & 0.21515 & 0.17973 & & & \\
\hline$\Delta \mathrm{p}^{\mathrm{r}}-$ ner $_{-1}$ & +0.06267 & 0.39051 & 0.36334 & & & \\
\hline$\Delta \mathrm{p}^{\mathrm{f}}-\mathrm{sen}_{-1}$ & +0.07600 & 0.19351 & 0.22169 & & & \\
\hline$\Delta \mathrm{p}^{\mathrm{r}}-\mathrm{sen}_{-1}$ & -0.82466 & 0.57442 & 0.53762 & -0.52937 & 0.32328 & 0.31079 \\
\hline$\Delta \mathrm{p}^{\mathrm{f}}{ }_{\mathrm{Ci}} \mathrm{v}_{-1}$ & -0.14956 & 0.26345 & 0.22458 & & & \\
\hline$\Delta \mathrm{p}^{\mathrm{r}} \mathrm{CiV}_{-1}$ & -0.29143 & 0.57943 & 0.51154 & & & \\
\hline$\Delta \mathrm{p}^{\mathrm{f}}-\operatorname{tog}_{-1}$ & +0.01550 & 0.13096 & 0.10861 & & & \\
\hline$\Delta \mathrm{p}^{\mathrm{r}}-\operatorname{tog}_{-1}$ & +0.23480 & 0.26583 & 0.21833 & & & \\
\hline$\Delta \mathrm{m}_{-1}$ & +0.05779 & 0.18057 & 0.19561 & & & \\
\hline$\Delta r_{-1}$ & -1.24930 & 1.06010 & 1.2475 & & & \\
\hline $\mathrm{ecm}^{\mathrm{fr}}-1$ & -0.13122 & 0.07398 & 0.07045 & -0.15910 & 0.05327 & 0.05053 \\
\hline $\mathrm{ecm}^{\mathrm{r}}-\mathrm{ben}_{-1}$ & -0.24658 & 0.11564 & 0.13658 & -0.27722 & 0.09600 & 0.09222 \\
\hline$e \mathrm{~cm}^{\mathrm{f}}-\mathrm{ben}_{-1}$ & -0.31367 & 0.08445 & 0.08439 & -0.35905 & 0.06284 & 0.05720 \\
\hline$\sigma$ & +0.02856 & & & +0.02755 & & \\
\hline$\Delta \mathrm{p}^{\mathrm{r}}$-ben & \multicolumn{3}{|c|}{ Unrestricted } & \multicolumn{3}{|c|}{ Restricted } \\
\hline Variable & coeff. & s.e. & h.c.s.e. & coeff. & s.e. & h.c.s.e. \\
\hline$\Delta \mathrm{p}^{\mathrm{f}}-\mathrm{bfa} \mathrm{a}_{-1}$ & +0.14791 & 0.07781 & 0.07385 & 0.11002 & 0.05111 & 0.05279 \\
\hline$\Delta \mathrm{p}^{\mathrm{r}}-\mathrm{bfa} \mathrm{a}_{-1}$ & -0.07086 & 0.13062 & 0.09373 & & & \\
\hline$\Delta \mathrm{p}^{\mathrm{f}}$-ben & -0.00628 & 0.06854 & 0.06697 & & & \\
\hline$\Delta \mathrm{p}^{\mathrm{r}}$-ben $\mathrm{n}_{-1}$ & +0.29751 & 0.12949 & 0.12766 & 0.24432 & 0.08745 & 0.07803 \\
\hline$\Delta \mathrm{p}^{\mathrm{f}}-\mathrm{mal}_{-1}$ & -0.06200 & 0.08100 & 0.07149 & & & \\
\hline$\Delta \mathrm{p}^{\mathrm{r}}-\mathrm{mal}{ }_{-1}$ & -0.00976 & 0.09582 & 0.07814 & & & \\
\hline$\Delta \mathrm{p}^{\mathrm{f}}-\mathrm{ner}_{-1}$ & 0.06570 & 0.10742 & 0.09056 & & & \\
\hline$\Delta \mathrm{p}^{\mathrm{r}}-$ ner $_{-1}$ & -0.02297 & 0.19549 & 0.21337 & & & \\
\hline$\Delta \mathrm{p}^{\mathrm{f}}-\mathrm{sen}_{-1}$ & -0.02268 & 0.09667 & 0.08878 & & & \\
\hline$\Delta \mathrm{p}^{\mathrm{r}_{-}} \operatorname{sen}_{-1}$ & +0.10487 & 0.28697 & 0.26151 & & & \\
\hline$\Delta \mathrm{p}^{\mathrm{f}}-\mathrm{Ci} \mathrm{v}_{-1}$ & -0.11131 & 0.13158 & 0.08990 & & & \\
\hline$\Delta \mathrm{p}^{\mathrm{r}_{-}} \mathrm{Ci \textrm {v } _ { - 1 }}$ & +0.30242 & 0.28954 & 0.26028 & & & \\
\hline$\Delta \mathrm{p}^{\mathrm{f}}-\operatorname{tog}_{-1}$ & -0.09632 & 0.06551 & 0.06602 & -0.10388 & 0.04272 & 0.03643 \\
\hline$\Delta \mathrm{p}^{\mathrm{r}}-\operatorname{tog}_{-1}$ & +0.02849 & 0.13284 & 0.10178 & & & \\
\hline$\Delta \mathrm{m}_{-1}$ & +0.05749 & 0.09031 & 0.09635 & & & \\
\hline$\Delta r_{-1}$ & -0.14589 & 0.53135 & 0.83599 & & & \\
\hline $\mathrm{ecm}^{\mathrm{fr}}-1$ & -0.03690 & 0.03711 & 0.03153 & -0.06343 & 0.02792 & 0.02771 \\
\hline $\mathrm{ecm}^{\mathrm{r}}$-ben -1 & -0.28238 & 0.06222 & 0.06965 & -0.29743 & 0.05433 & 0.05873 \\
\hline$e^{f} m^{f}-b_{-1}$ & -0.08813 & 0.04424 & 0.04467 & -0.09076 & 0.03352 & 0.03626 \\
\hline$\sigma$ & +0.01426 & & & +0.01340 & & \\
\hline
\end{tabular}


Table A1 (Continued)

\begin{tabular}{|c|c|c|c|c|c|c|}
\hline$\Delta \mathrm{p}^{\mathrm{f}}-\mathrm{mal}$ & \multicolumn{3}{|c|}{ Unrestricted } & \multicolumn{3}{|c|}{ Restricted } \\
\hline Variable & coeff. & s.e. & h.c.s.e. & coeff. & s.e. & h.c.s.e. \\
\hline$\Delta \mathrm{p}^{\mathrm{f}}-\mathrm{b} f \mathrm{a}_{-1}$ & +0.07121 & 0.10827 & 0.10612 & & & \\
\hline$\Delta \mathrm{p}^{\mathrm{r}}-\mathrm{b} f \mathrm{a}_{-1}$ & -0.13323 & 0.18220 & 0.21470 & -0.31374 & 0.13849 & 0.16119 \\
\hline$\Delta \mathrm{p}^{\mathrm{f}}-\mathrm{ben}_{-1}$ & +0.12188 & 0.09190 & 0.08634 & +0.14521 & 0.06568 & 0.06415 \\
\hline$\Delta \mathrm{p}^{\mathrm{r}}-\mathrm{ben}_{-1}$ & -0.09334 & 0.17884 & 0.12057 & & & \\
\hline$\Delta \mathrm{p}^{\mathrm{f}}-\mathrm{mal}_{-1}$ & -0.08955 & 0.11571 & 0.12966 & & & \\
\hline$\Delta \mathrm{p}^{\mathrm{r}}-\mathrm{mal}_{-1}$ & -0.23395 & 0.15515 & 0.13071 & -0.17605 & 0.10550 & 0.09336 \\
\hline$\Delta \mathrm{p}^{\mathrm{f}}-$ ner $_{-1}$ & +0.15267 & 0.15005 & 0.14004 & & & \\
\hline$\Delta \mathrm{p}^{\mathrm{r}}-$ ner $_{-1}$ & -0.08867 & 0.27076 & 0.26683 & & & \\
\hline$\Delta \mathrm{p}^{\mathrm{f}}-\mathrm{sen}_{-1}$ & -0.04496 & 0.13494 & 0.12704 & & & \\
\hline$\Delta \mathrm{p}^{\mathrm{r}}-\mathrm{sen}_{-1}$ & +0.26296 & 0.40813 & 0.34162 & & & \\
\hline$\Delta \mathrm{p}^{\mathrm{f}}-\mathrm{Civ}_{-1}$ & -0.24974 & 0.19077 & 0.17683 & & & \\
\hline$\Delta \mathrm{p}^{\mathrm{r}}-\mathrm{Civ}_{-1}$ & +0.62398 & 0.40007 & 0.40245 & & & \\
\hline$\Delta \mathrm{p}^{\mathrm{f}}-\operatorname{tog}_{-1}$ & -0.00926 & 0.09028 & 0.07906 & & & \\
\hline$\Delta \mathrm{p}^{\mathrm{r}}-\operatorname{tog}_{-1}$ & -0.07954 & 0.18280 & 0.13216 & & & \\
\hline$\Delta \mathrm{m}_{-1}$ & -0.19424 & 0.12368 & 0.14694 & -0.25420 & 0.10002 & 0.11380 \\
\hline$\Delta r_{-1}$ & -0.71551 & 0.72219 & 0.62875 & -1.44860 & 0.53339 & 0.58475 \\
\hline $\mathrm{ecm}^{\mathrm{fr}}-1$ & -0.08426 & 0.05538 & 0.05447 & -0.09486 & 0.04273 & 0.04057 \\
\hline $\mathrm{ecm}^{\mathrm{r}}-\mathrm{mal}_{-1}$ & +0.05569 & 0.15194 & 0.13960 & & & \\
\hline $\mathrm{ecm}^{\mathrm{f}}-\mathrm{mal}_{-1}$ & -0.20535 & 0.05390 & 0.05213 & -0.18944 & 0.04212 & 0.04497 \\
\hline$\sigma$ & +0.01977 & & & +0.01891 & & \\
\hline$\Delta \mathrm{p}^{\mathrm{r}}-\mathrm{mal}$ & \multicolumn{3}{|c|}{ Unrestricted } & \multicolumn{3}{|c|}{ Restricted } \\
\hline Variable & coeff. & s.e. & h.c.s.e. & coeff. & s.e. & h.c.s.e. \\
\hline$\Delta \mathrm{p}^{\mathrm{f}}-\mathrm{bf} \mathrm{a}_{-1}$ & -0.17433 & 0.08857 & 0.13829 & & & \\
\hline$\Delta \mathrm{p}^{\mathrm{r}}-\mathrm{bf} \mathrm{a}_{-1}$ & +0.18561 & 0.14904 & 0.17139 & 0.19032 & 0.11280 & 0.08319 \\
\hline$\Delta \mathrm{p}^{\mathrm{f}}$-ben & +0.04839 & 0.07511 & 0.11039 & & & \\
\hline$\Delta \mathrm{p}^{\mathrm{r}}$-ben $\mathrm{n}_{-1}$ & -0.06482 & 0.14609 & 0.13844 & & & \\
\hline$\Delta \mathrm{p}^{\mathrm{f}}-\mathrm{mal}_{-1}$ & +0.04949 & 0.09449 & 0.08756 & & & \\
\hline$\Delta \mathrm{p}^{\mathrm{r}}-\mathrm{mal}_{-1}$ & +0.05642 & 0.12627 & 0.10592 & & & \\
\hline$\Delta \mathrm{p}^{\mathrm{f}}-\mathrm{ner}_{-1}$ & +0.08301 & 0.12276 & 0.09430 & & & \\
\hline$\Delta \mathrm{p}^{\mathrm{r}}-$ ner $_{-1}$ & +0.17322 & 0.22107 & 0.20841 & & & \\
\hline$\Delta \mathrm{p}^{\mathrm{f}}-\mathrm{sen}_{-1}$ & +0.08660 & 0.11034 & 0.09207 & & & \\
\hline$\Delta \mathrm{p}^{\mathrm{r}}-\mathrm{sen}_{-1}$ & -0.22998 & 0.33335 & 0.28186 & & & \\
\hline$\Delta \mathrm{p}^{\mathrm{f}}-\mathrm{Civ}_{-1}$ & +0.23757 & 0.15566 & 0.14424 & & & \\
\hline$\Delta \mathrm{p}^{\mathrm{r}}-\mathrm{Ci} \mathrm{v}_{-1}$ & -0.32315 & 0.32735 & 0.26977 & & & \\
\hline$\Delta \mathrm{p}^{\mathrm{f}}-\operatorname{tog}_{-1}$ & -0.05306 & 0.07382 & 0.06061 & & & \\
\hline$\Delta \mathrm{p}^{\mathrm{r}}-\operatorname{tog}_{-1}$ & +0.02867 & 0.14958 & 0.19192 & & & \\
\hline$\Delta \mathrm{m}_{-1}$ & +0.00073 & 0.10119 & 0.11316 & & & \\
\hline$\Delta r_{-1}$ & +0.17791 & 0.59053 & 0.46049 & & & \\
\hline $\mathrm{ecm}^{\mathrm{fr}}-1$ & +0.00671 & 0.04497 & 0.04742 & & & \\
\hline $\mathrm{ecm}^{\mathrm{r}}-\mathrm{mal}_{-1}$ & -0.49746 & 0.12180 & 0.14523 & -0.46227 & 0.090164 & 0.12244 \\
\hline $\mathrm{ecm}^{\mathrm{f}}-\mathrm{mal}_{-1}$ & +0.06135 & 0.04233 & 0.03680 & & & \\
\hline$\sigma$ & +0.01618 & & & +0.01589 & & \\
\hline
\end{tabular}


Table A1 (Continued)

\begin{tabular}{|c|c|c|c|c|c|c|}
\hline$\Delta \mathrm{p}^{\mathrm{f}}-\mathrm{ner}$ & \multicolumn{3}{|c|}{ Unrestricted } & \multicolumn{3}{|c|}{ Restricted } \\
\hline Variable & coeff. & s.e. & h.c.s.e. & coeff. & s.e. & h.c.s.e. \\
\hline$\Delta \mathrm{p}^{\mathrm{f}}-\mathrm{b} \mathrm{fa}_{-1}$ & +0.10768 & 0.08901 & 0.09147 & & & \\
\hline$\Delta \mathrm{p}^{\mathrm{r}}-\mathrm{bfa}-1$ & +0.25865 & 0.15072 & 0.12747 & & & \\
\hline$\Delta \mathrm{p}^{\mathrm{f}}$-ben & -0.02091 & 0.07533 & 0.06286 & & & \\
\hline$\Delta \mathrm{p}^{\mathrm{r}}$-ben -1 & -0.02975 & 0.14430 & 0.14535 & & & \\
\hline$\Delta \mathrm{p}^{\mathrm{f}}-\mathrm{mal}_{-1}$ & +0.01358 & 0.09220 & 0.09688 & & & \\
\hline$\Delta \mathrm{p}^{\mathrm{r}}-\mathrm{mal}-1$ & +0.01265 & 0.11035 & 0.07724 & & & \\
\hline$\Delta \mathrm{p}^{\mathrm{f}}-$ ner $_{-1}$ & +0.12545 & 0.12664 & 0.14302 & & & \\
\hline$\Delta \mathrm{p}^{\mathrm{r}}-$ ner $_{-1}$ & +0.05262 & 0.23013 & 0.27115 & & & \\
\hline$\Delta \mathrm{p}^{\mathrm{f}}-$ sen $_{-1}$ & -0.04389 & 0.11090 & 0.11223 & & & \\
\hline$\Delta \mathrm{p}^{\mathrm{r}}-$ sen $_{-1}$ & +0.27876 & 0.33163 & 0.32420 & & & \\
\hline$\Delta \mathrm{p}^{\mathrm{f}}-\mathrm{Ci} \mathrm{v}_{-1}$ & -0.17785 & 0.15624 & 0.13294 & & & \\
\hline$\Delta \mathrm{p}^{\mathrm{r}}-\mathrm{Civ_{-1 }}$ & +0.01788 & 0.33118 & 0.29792 & & & \\
\hline$\Delta \mathrm{p}^{\mathrm{f}}-\operatorname{tog}_{-1}$ & +0.08365 & 0.07553 & 0.07613 & 0.08594 & 0.05252 & 0.03857 \\
\hline$\Delta \mathrm{p}^{\mathrm{r}}-\operatorname{tog}_{-1}$ & +0.06161 & 0.15122 & 0.13761 & & & \\
\hline$\Delta \mathrm{m}_{-1}$ & +0.08466 & 0.10394 & 0.09397 & & & \\
\hline$\Delta r_{-1}$ & +0.45541 & 0.59581 & 0.90069 & & & \\
\hline $\mathrm{ecm}^{\mathrm{fr}}-1$ & -0.04910 & 0.04236 & 0.04067 & -0.06322 & 0.03605 & 0.04023 \\
\hline $\mathrm{ecm}^{\mathrm{r}}$-ner -1 & -0.14756 & 0.12781 & 0.11065 & & & \\
\hline $\mathrm{ecm}^{\mathrm{f}}$-ner -1 & -0.15881 & 0.05079 & 0.05664 & -0.13621 & 0.04387 & 0.05175 \\
\hline$\sigma$ & & +0.01635 & & +0.01610 & & \\
\hline$\Delta \mathrm{p}^{\mathrm{r}}-$ ner & & restrict & & & estricte & \\
\hline Variable & coeff. & s.e. & h.c.s.e. & coeff. & s.e. & h.c.s.e. \\
\hline$\Delta \mathrm{p}^{\mathrm{f}}-\mathrm{b} f \mathrm{a}_{-1}$ & +0.10183 & 0.04839 & 0.04466 & +0.09359 & 0.03676 & 0.03144 \\
\hline$\Delta \mathrm{p}^{\mathrm{r}}-\mathrm{bfa} \mathrm{a}_{-1}$ & +0.04691 & 0.08187 & 0.10619 & & & \\
\hline$\Delta \mathrm{p}^{\mathrm{f}}$-ben $\mathrm{n}_{-1}$ & -0.11252 & 0.04092 & 0.04761 & -0.11177 & 0.03241 & 0.03103 \\
\hline$\Delta \mathrm{p}^{\mathrm{r}}$-ben $\mathrm{n}_{-1}$ & +0.15007 & 0.07842 & 0.09878 & +0.15075 & 0.05566 & 0.06200 \\
\hline$\Delta \mathrm{p}^{\mathrm{f}}-\mathrm{mal}{ }_{-1}$ & -0.00956 & 0.05008 & 0.05861 & & & \\
\hline$\Delta \mathrm{p}^{\mathrm{r}}-\mathrm{mal}{ }_{-1}$ & +0.09093 & 0.05994 & 0.05571 & +0.08980 & 0.04905 & 0.03792 \\
\hline$\Delta \mathrm{p}^{\mathrm{f}}-\mathrm{ner}_{-1}$ & +0.10796 & 0.06862 & 0.06789 & +0.10455 & 0.04965 & 0.04616 \\
\hline$\Delta \mathrm{p}^{\mathrm{r}}-\mathrm{ner}_{-1}$ & -0.01043 & 0.12443 & 0.12786 & & & \\
\hline$\Delta \mathrm{p}^{\mathrm{f}}-\operatorname{sen}_{-1}$ & +0.03649 & 0.06024 & 0.05663 & & & \\
\hline$\Delta \mathrm{p}^{\mathrm{r}}$ sen $_{-1}$ & +0.49779 & 0.17997 & 0.17618 & +0.52212 & 0.12735 & 0.14743 \\
\hline$\Delta \mathrm{p}^{\mathrm{f}}-\mathrm{Ci} \mathrm{v}_{-1}$ & -0.13580 & 0.08460 & 0.08838 & -0.09959 & 0.06204 & 0.05941 \\
\hline$\Delta \mathrm{p}^{\mathrm{r}_{-}} \mathrm{Ci \textrm {v } _ { - 1 }}$ & +0.09773 & 0.17998 & 0.19894 & & & \\
\hline$\Delta \mathrm{p}^{\mathrm{f}}-\operatorname{tog}_{-1}$ & -0.07927 & 0.04095 & 0.04598 & -0.09674 & 0.03144 & 0.03406 \\
\hline$\Delta \mathrm{p}^{\mathrm{r}}-\operatorname{tog}_{-1}$ & +0.00951 & 0.08219 & 0.09246 & & & \\
\hline$\Delta \mathrm{m}_{-1}$ & +0.10346 & 0.05637 & 0.05314 & 0.08551 & 0.04592 & 0.04282 \\
\hline$\Delta r_{-1}$ & -0.16907 & 0.32321 & 0.32984 & & & \\
\hline$e^{f r}{ }_{-1}$ & +0.01154 & 0.02290 & 0.02054 & & & \\
\hline $\mathrm{ecm}^{\mathrm{r}}$-ner -1 & -0.19122 & 0.06593 & 0.05790 & -0.17603 & 0.05683 & 0.04631 \\
\hline$e^{f}-$ ner -1 & -0.00526 & 0.02588 & 0.02225 & & & \\
\hline$\sigma$ & +0.00889 & & & +0.00825 & & \\
\hline
\end{tabular}


Table A1 (Continued)

\begin{tabular}{|c|c|c|c|c|c|c|}
\hline$\Delta \mathrm{p}^{\mathrm{f}}-\mathrm{sen}$ & \multicolumn{3}{|c|}{ Unrestricted } & \multicolumn{3}{|c|}{ Restricted } \\
\hline Variable & coeff. & s.e. & h.c.s.e. & coeff. & s.e. & h.c.s.e. \\
\hline$\Delta \mathrm{p}^{\mathrm{f}}-\mathrm{bfa} \mathrm{a}_{-1}$ & -0.06762 & 0.099337 & 0.10484 & & & \\
\hline$\Delta \mathrm{p}^{\mathrm{r}}-\mathrm{bfa} \mathrm{a}_{-1}$ & +0.14462 & 0.16668 & 0.17114 & & & \\
\hline$\Delta \mathrm{p}^{\mathrm{f}}$-ben -1 & -0.02024 & 0.08388 & 0.07981 & & & \\
\hline$\Delta \mathrm{p}^{\mathrm{r}}$-ben $\mathrm{b}_{-1}$ & +0.13953 & 0.16265 & 0.17475 & & & \\
\hline$\Delta \mathrm{p}^{\mathrm{f}}-\mathrm{mal}_{-1}$ & +0.20695 & 0.10351 & 0.11563 & & & \\
\hline$\Delta \mathrm{p}^{\mathrm{r}}-\mathrm{mal}{ }_{-1}$ & -0.07267 & 0.12185 & 0.08664 & & & \\
\hline$\Delta \mathrm{p}^{\mathrm{f}}$-ner -1 & +0.03066 & 0.13727 & 0.16422 & +0.19979 & 0.08414 & 0.08590 \\
\hline$\Delta \mathrm{p}^{\mathrm{r}}$-ner ${ }_{-1}$ & +0.18459 & 0.24042 & 0.25966 & & & \\
\hline$\Delta \mathrm{p}^{\mathrm{f}}-\mathrm{sen}_{-1}$ & -0.00947 & 0.13118 & 0.12097 & & & \\
\hline$\Delta \mathrm{p}^{\mathrm{r}}$ sen $_{-1}$ & -0.06533 & 0.36491 & 0.33176 & & & \\
\hline$\Delta \mathrm{p}^{\mathrm{f}}-\mathrm{Ci} \mathrm{v}_{-1}$ & -0.17027 & 0.17005 & 0.14694 & -0.18513 & 0.11541 & 0.09435 \\
\hline$\Delta \mathrm{p}^{\mathrm{r}_{-}} \mathrm{Civ}_{-1}$ & -0.33154 & 0.37084 & 0.36999 & & & \\
\hline$\Delta \mathrm{p}^{\mathrm{f}}-\operatorname{tog}_{-1}$ & +0.09697 & 0.08365 & 0.08463 & & & \\
\hline$\Delta p^{r}-\operatorname{tog}_{-1}$ & -0.08592 & 0.16795 & 0.17526 & & & \\
\hline$\Delta \mathrm{m}_{-1}$ & +0.22401 & 0.11714 & 0.10804 & +0.18322 & 0.09672 & 0.09414 \\
\hline$\Delta r_{-1}$ & -1.10200 & 0.65697 & 0.68066 & -0.77947 & 0.50437 & 0.44990 \\
\hline $\mathrm{ecm}^{\mathrm{fr}}-1$ & -0.16995 & 0.08053 & 0.08213 & -0.18235 & 0.05997 & 0.06674 \\
\hline $\mathrm{ecm}^{\mathrm{r}}-\mathrm{sen}_{-1}$ & -0.13971 & 0.15294 & 0.18735 & & & \\
\hline $\mathrm{ecm}^{\mathrm{f}}-\mathrm{sen}_{-1}$ & -0.23444 & 0.07664 & 0.07748 & -0.22138 & 0.06114 & 0.06585 \\
\hline$\sigma$ & +0.01806 & & & +0.01730 & & \\
\hline
\end{tabular}

\begin{tabular}{|c|c|c|c|c|c|c|}
\hline$\Delta \mathrm{p}^{\mathrm{r}}-\mathrm{sen}$ & \multicolumn{3}{|c|}{ Unrestricted } & \multicolumn{3}{|c|}{ Restricted } \\
\hline Variable & coeff. & s.e. & h.c.s.e. & coeff. & s.e. & h.c.s.e. \\
\hline$\Delta \mathrm{p}^{\mathrm{f}}-\mathrm{bfa} \mathrm{a}_{-1}$ & -0.01684 & 0.03481 & 0.03367 & & & \\
\hline$\Delta \mathrm{p}^{\mathrm{r}}-\mathrm{bfa} \mathrm{a}_{-1}$ & +0.12279 & 0.05842 & 0.06832 & 0.11214 & 0.04310 & 0.04719 \\
\hline$\Delta \mathrm{p}^{\mathrm{f}}$-ben & +0.04316 & 0.02935 & 0.02399 & 0.04560 & 0.01872 & 0.01734 \\
\hline$\Delta \mathrm{p}^{\mathrm{r}}$-ben -1 & +0.03300 & 0.05691 & 0.05434 & & & \\
\hline$\Delta \mathrm{p}^{\mathrm{f}}-\mathrm{mal}{ }_{-1}$ & -0.02703 & 0.03623 & 0.03945 & -0.04922 & 0.02804 & 0.02677 \\
\hline$\Delta \mathrm{p}^{\mathrm{r}}-\mathrm{mal}{ }_{-1}$ & -0.00000 & 0.04271 & 0.03574 & & & \\
\hline$\Delta \mathrm{p}^{\mathrm{f}}-$ ner $_{-1}$ & -0.02006 & 0.04808 & 0.05291 & & & \\
\hline$\Delta \mathrm{p}^{\mathrm{r}}-$ ner $_{-1}$ & +0.17206 & 0.08431 & 0.10298 & 0.14923 & 0.05313 & 0.05358 \\
\hline$\Delta \mathrm{p}^{\mathrm{f}}-\mathrm{sen}_{-1}$ & +0.00712 & 0.04554 & 0.04033 & & & \\
\hline$\Delta \mathrm{p}^{\mathrm{r}}-$ sen $_{-1}$ & -0.10002 & 0.12779 & 0.13460 & & & \\
\hline$\Delta \mathrm{p}^{\mathrm{f}}-\mathrm{Civ}_{-1}$ & -0.09967 & 0.05950 & 0.06421 & -0.12653 & 0.04159 & 0.03914 \\
\hline$\Delta \mathrm{p}^{\mathrm{r}}-\mathrm{Civ_{-1 }}$ & -0.16452 & 0.12987 & 0.12616 & & & \\
\hline$\Delta \mathrm{p}^{\mathrm{f}}-\operatorname{tog}_{-1}$ & +0.07463 & 0.02927 & 0.03589 & 0.04801 & 0.02021 & 0.02656 \\
\hline$\Delta \mathrm{p}^{\mathrm{r}}-\operatorname{tog}_{-1}$ & +0.01652 & 0.05885 & 0.07361 & & & \\
\hline$\Delta \mathrm{m}_{-1}$ & +0.11083 & 0.04094 & 0.04076 & 0.10519 & 0.03176 & 0.03389 \\
\hline$\Delta r_{-1}$ & -0.81023 & 0.23004 & 0.24646 & -0.71760 & 0.17426 & 0.16541 \\
\hline$e^{f r}-1$ & -0.02389 & 0.02665 & 0.02415 & & & \\
\hline $\mathrm{ecm}^{\mathrm{r}}-\mathrm{sen}_{-1}$ & -0.25499 & 0.05082 & 0.05107 & -0.23499 & 0.03643 & 0.04041 \\
\hline $\mathrm{ecm}^{\mathrm{f}}-\mathrm{sen}_{-1}$ & -0.05369 & 0.02476 & 0.02545 & -0.03702 & 0.01284 & 0.01366 \\
\hline$\sigma$ & +0.00633 & & & +0.00602 & & \\
\hline
\end{tabular}


Table A1 (Continued)

\begin{tabular}{|c|c|c|c|c|c|c|}
\hline$\Delta \mathrm{p}^{\mathrm{f}}-\mathrm{CiV}$ & \multicolumn{3}{|c|}{ Unrestricted } & \multicolumn{3}{|c|}{ Restricted } \\
\hline Variable & coeff. & s.e. & h.c.s.e. & coeff. & s.e. & h.c.s.e. \\
\hline$\Delta \mathrm{p}^{\mathrm{f}}-\mathrm{bfa} \mathrm{a}_{-1}$ & -0.04100 & 0.08582 & 0.10190 & & & \\
\hline$\Delta \mathrm{p}^{\mathrm{r}}-\mathrm{bf} \mathrm{a}_{-1}$ & -0.13904 & 0.14439 & 0.14497 & & & \\
\hline$\Delta \mathrm{p}^{\mathrm{f}}-\mathrm{ben}_{-1}$ & +0.09017 & 0.07212 & 0.07306 & +0.07319 & 0.04222 & 0.05313 \\
\hline$\Delta \mathrm{p}^{\mathrm{r}}$-ben $\mathrm{b}_{-1}$ & +0.13760 & 0.13886 & 0.13562 & & & \\
\hline$\Delta \mathrm{p}^{\mathrm{f}}-\mathrm{mal}{ }_{-1}$ & +0.13206 & 0.08827 & 0.07396 & & & \\
\hline$\Delta \mathrm{p}^{\mathrm{r}}-\mathrm{mal}_{-1}$ & +0.04021 & 0.10568 & 0.10114 & & & \\
\hline$\Delta \mathrm{p}^{\mathrm{f}}-\mathrm{ner}_{-1}$ & +0.12739 & 0.11880 & 0.11750 & & & \\
\hline$\Delta \mathrm{p}^{\mathrm{r}}-\mathrm{ner}_{-1}$ & -0.02766 & 0.20969 & 0.22167 & & & \\
\hline$\Delta \mathrm{p}^{\mathrm{f}}-\mathrm{sen}_{-1}$ & -0.00751 & 0.10620 & 0.09976 & & & \\
\hline$\Delta \mathrm{p}^{\mathrm{r}}$ sen $_{-1}$ & -0.18757 & 0.31523 & 0.26222 & & & \\
\hline$\Delta \mathrm{p}^{\mathrm{f}}-\mathrm{Ci} \mathrm{v}_{-1}$ & +0.11093 & 0.14509 & 0.13520 & & & \\
\hline$\Delta \mathrm{p}^{\mathrm{r}}-\mathrm{Civ_{-1 }}$ & -0.19940 & 0.31830 & 0.41297 & & & \\
\hline$\Delta \mathrm{p}^{\mathrm{f}}-\operatorname{tog}_{-1}$ & -0.02038 & 0.07126 & 0.05803 & & & \\
\hline$\Delta \mathrm{p}^{\mathrm{r}}-\operatorname{tog}_{-1}$ & -0.02982 & 0.14552 & 0.14463 & & & \\
\hline$\Delta \mathrm{m}_{-1}$ & +0.08254 & 0.09815 & 0.09431 & +0.15710 & 0.07266 & 0.07270 \\
\hline$\Delta r_{-1}$ & -0.50074 & 0.56443 & 0.47436 & & & \\
\hline$e^{f f r}{ }_{-1}$ & -0.06995 & 0.03889 & 0.04628 & -0.06376 & 0.02886 & 0.03291 \\
\hline$\sigma$ & +0.01577 & & & +0.01528 & & \\
\hline$\Delta \mathrm{p}^{\mathrm{r}}-\mathrm{Civ}$ & & restrict & & & estricte & \\
\hline Variable & coeff. & s.e. & h.c.s.e. & coeff. & s.e. & h.c.s.e. \\
\hline$\Delta \mathrm{p}^{\mathrm{f}}-\mathrm{bfa} \mathrm{a}_{-1}$ & -0.01466 & 0.04125 & 0.04812 & & & \\
\hline$\Delta \mathrm{p}^{\mathrm{r}}-\mathrm{b} f \mathrm{a}_{-1}$ & -0.02497 & 0.06941 & 0.09343 & & & \\
\hline$\Delta \mathrm{p}^{\mathrm{f}}-\mathrm{ben}_{-1}$ & -0.00140 & 0.03467 & 0.03733 & & & \\
\hline$\Delta \mathrm{p}^{\mathrm{r}}$-ben $\mathrm{n}_{-1}$ & -0.00237 & 0.06675 & 0.06581 & & & \\
\hline$\Delta \mathrm{p}^{\mathrm{f}}-\mathrm{mal}_{-1}$ & +0.04269 & 0.04243 & 0.03887 & & & \\
\hline$\Delta \mathrm{p}^{\mathrm{r}}-\mathrm{mal}_{-1}$ & +0.10463 & 0.05080 & 0.05002 & +0.06995 & 0.03396 & 0.03356 \\
\hline$\Delta \mathrm{p}^{\mathrm{f}}-\mathrm{ner}_{-1}$ & -0.00394 & 0.05711 & 0.06075 & & & \\
\hline$\Delta \mathrm{p}^{\mathrm{r}}-$ ner $_{-1}$ & +0.14530 & 0.10079 & 0.10611 & +0.11335 & 0.05655 & 0.04411 \\
\hline$\Delta \mathrm{p}^{\mathrm{f}}-\mathrm{sen}_{-1}$ & +0.00134 & 0.05105 & 0.04456 & & & \\
\hline$\Delta \mathrm{p}^{\mathrm{r}}-\mathrm{sen}_{-1}$ & +0.20192 & 0.15152 & 0.10675 & +0.20184 & 0.09025 & 0.07171 \\
\hline$\Delta \mathrm{p}^{\mathrm{f}}-\mathrm{Ci} \mathrm{v}_{-1}$ & -0.06282 & 0.06974 & 0.07518 & -0.11386 & 0.04173 & 0.04730 \\
\hline$\Delta \mathrm{p}^{\mathrm{r}}{ }_{\mathrm{Ci}} \mathrm{v}_{-1}$ & -0.09186 & 0.15300 & 0.25076 & & & \\
\hline$\Delta \mathrm{p}^{\mathrm{f}}-\operatorname{tog}_{-1}$ & -0.05939 & 0.03426 & 0.03299 & -0.04104 & 0.02212 & 0.02202 \\
\hline$\Delta \mathrm{p}^{\mathrm{r}}-\operatorname{tog}_{-1}$ & -0.08338 & 0.06995 & 0.07831 & & & \\
\hline$\Delta \mathrm{m}_{-1}$ & +0.09966 & 0.04718 & 0.04658 & +0.09701 & 0.03606 & 0.03400 \\
\hline$\Delta r_{-1}$ & -0.02269 & 0.27131 & 0.26728 & & & \\
\hline $\mathrm{ecm}^{\mathrm{fr}}-1$ & -0.02744 & 0.01869 & 0.01978 & -0.02212 & 0.01335 & 0.01131 \\
\hline$\sigma$ & +0.00758 & & & +0.00713 & & \\
\hline
\end{tabular}


Table A1 (Continued)

\begin{tabular}{|c|c|c|c|c|c|c|}
\hline$\Delta \mathrm{p}^{\mathrm{f}}-\mathrm{tog}$ & \multicolumn{3}{|c|}{ Unrestricted } & \multicolumn{3}{|c|}{ Restricted } \\
\hline Variable & coeff. & s.e. & h.c.s.e. & coeff. & s.e. & h.c.s.e. \\
\hline$\Delta \mathrm{p}^{\mathrm{f}}-\mathrm{bf} \mathrm{a}_{-1}$ & -0.15221 & 0.14916 & 0.13687 & & & \\
\hline$\Delta \mathrm{p}^{\mathrm{r}}-\mathrm{bfa} \mathrm{a}_{-1}$ & +0.42100 & 0.25434 & 0.20638 & 0.45925 & 0.18614 & 0.16717 \\
\hline$\Delta \mathrm{p}^{\mathrm{f}}-\mathrm{ben}_{-1}$ & +0.21498 & 0.12530 & 0.10468 & & & \\
\hline$\Delta \mathrm{p}^{\mathrm{r}}$-ben $\mathrm{b}_{-1}$ & -0.15839 & 0.24211 & 0.18816 & & & \\
\hline$\Delta \mathrm{p}^{\mathrm{f}}-\mathrm{mal}_{-1}$ & +0.20217 & 0.15387 & 0.17611 & & & \\
\hline$\Delta \mathrm{p}^{\mathrm{r}}-\mathrm{mal}_{-1}$ & -0.12691 & 0.18457 & 0.22668 & & & \\
\hline$\Delta \mathrm{p}^{\mathrm{f}}-\mathrm{ner}_{-1}$ & +0.17214 & 0.20539 & 0.16234 & & & \\
\hline$\Delta \mathrm{p}^{\mathrm{r}}-$ ner $_{-1}$ & +0.00348 & 0.37511 & 0.37397 & & & \\
\hline$\Delta \mathrm{p}^{\mathrm{f}}-\mathrm{sen}_{-1}$ & +0.12296 & 0.18348 & 0.20460 & & & \\
\hline$\Delta \mathrm{p}^{\mathrm{r}} \mathrm{sen}_{-1}$ & -0.95478 & 0.55292 & 0.50269 & & & \\
\hline$\Delta \mathrm{p}^{\mathrm{f}}-\mathrm{Civ}_{-1}$ & +0.02215 & 0.25290 & 0.22538 & & & \\
\hline$\Delta \mathrm{p}^{\mathrm{r}}-\mathrm{Ci} \mathrm{v}_{-1}$ & -0.07263 & 0.55914 & 0.55032 & & & \\
\hline$\Delta \mathrm{p}^{\mathrm{f}}-\operatorname{tog}_{-1}$ & +0.31720 & 0.12681 & 0.08940 & 0.29171 & 0.08316 & 0.08691 \\
\hline$\Delta \mathrm{p}^{\mathrm{r}}-\operatorname{tog}_{-1}$ & +0.77210 & 0.25672 & 0.24789 & 0.71959 & 0.18604 & 0.17273 \\
\hline$\Delta \mathrm{m}_{-1}$ & -0.08843 & 0.18125 & 0.15618 & & & \\
\hline$\Delta r_{-1}$ & -3.48280 & 0.99494 & 1.83820 & -3.14620 & 0.69784 & 1.07380 \\
\hline $\mathrm{ecm}^{\mathrm{fr}}{ }_{-1}$ & -0.08031 & 0.06840 & 0.06316 & & & \\
\hline$e^{r}-\operatorname{tog}_{-1}$ & -0.14980 & 0.12794 & 0.15269 & & & \\
\hline $\mathrm{ecm}^{\mathrm{f}}-\mathrm{tog}_{-1}$ & -0.12766 & 0.04853 & 0.04764 & -0.11475 & 0.04084 & 0.04882 \\
\hline$\sigma$ & +0.02725 & & & +0.02693 & & \\
\hline$\Delta \mathrm{p}^{\mathrm{r}}-\mathrm{tog}$ & \multicolumn{3}{|c|}{ Unrestricted } & \multicolumn{3}{|c|}{ Restricted } \\
\hline Variable & coeff. & s.e. & h.c.s.e. & coeff. & s.e. & h.c.s.e. \\
\hline$\Delta \mathrm{p}^{\mathrm{f}}-\mathrm{b} f \mathrm{a}_{-1}$ & +0.04382 & 0.06795 & 0.05918 & & & \\
\hline$\Delta \mathrm{p}^{\mathrm{r}}-\mathrm{bf} \mathrm{a}_{-1}$ & +0.14707 & 0.11598 & 0.13991 & & & \\
\hline$\Delta \mathrm{p}^{\mathrm{f}}-\mathrm{ben}_{-1}$ & -0.10554 & 0.05707 & 0.06302 & & & \\
\hline$\Delta \mathrm{p}^{\mathrm{r}}$-ben $\mathrm{n}_{-1}$ & +0.23976 & 0.11033 & 0.11493 & 0.20186 & 0.07508 & 0.08952 \\
\hline$\Delta \mathrm{p}^{\mathrm{f}}-\mathrm{mal}_{-1}$ & -0.13313 & 0.07010 & 0.07753 & -0.09392 & 0.05528 & 0.05731 \\
\hline$\Delta \mathrm{p}^{\mathrm{r}}-\mathrm{mal}_{-1}$ & +0.06453 & 0.08410 & 0.08349 & & & \\
\hline$\Delta \mathrm{p}^{\mathrm{f}}-\mathrm{ner}_{-1}$ & +0.12639 & 0.09353 & 0.08032 & 0.16006 & 0.07076 & 0.07543 \\
\hline$\Delta \mathrm{p}^{\mathrm{r}}-$ ner $_{-1}$ & +0.05173 & 0.17134 & 0.16376 & & & \\
\hline$\Delta \mathrm{p}^{\mathrm{f}}-\mathrm{sen}_{-1}$ & +0.09529 & 0.08354 & 0.07484 & 0.14226 & 0.05925 & 0.06813 \\
\hline$\Delta \mathrm{p}^{\mathrm{r}}$ sen $_{-1}$ & +0.22860 & 0.25200 & 0.23297 & & & \\
\hline$\Delta \mathrm{p}^{\mathrm{f}}{ }_{-} \mathrm{Civ}_{-1}$ & -0.03160 & 0.11524 & 0.10751 & & & \\
\hline$\Delta \mathrm{p}^{\mathrm{r}_{-}} \mathrm{Ci} \mathrm{v}_{-1}$ & +0.09611 & 0.25487 & 0.23547 & & & \\
\hline$\Delta \mathrm{p}^{\mathrm{f}}-\mathrm{tog}_{-1}$ & +0.04096 & 0.05786 & 0.05203 & & & \\
\hline$\Delta \mathrm{p}^{\mathrm{r}}-\operatorname{tog}_{-1}$ & +0.09109 & 0.11711 & 0.10852 & & & \\
\hline$\Delta \mathrm{m}_{-1}$ & +0.13853 & 0.08303 & 0.07737 & & & \\
\hline$\Delta r_{-1}$ & +0.26498 & 0.45388 & 0.76093 & & & \\
\hline$e \mathrm{~cm}^{\mathrm{fr}}-1$ & -0.02424 & 0.03120 & 0.02949 & & & \\
\hline$e \mathrm{~cm}^{\mathrm{r}}-\operatorname{tog}_{-1}$ & -0.26445 & 0.06108 & 0.07161 & -0.19044 & 0.04462 & 0.05609 \\
\hline$e^{f}{ }^{f}-\operatorname{tog}_{-1}$ & +0.03256 & 0.02284 & 0.02199 & & & \\
\hline$\sigma$ & +0.01241 & & & +0.01186 & & \\
\hline
\end{tabular}


Table A2: Summary statistics for Table A1 model

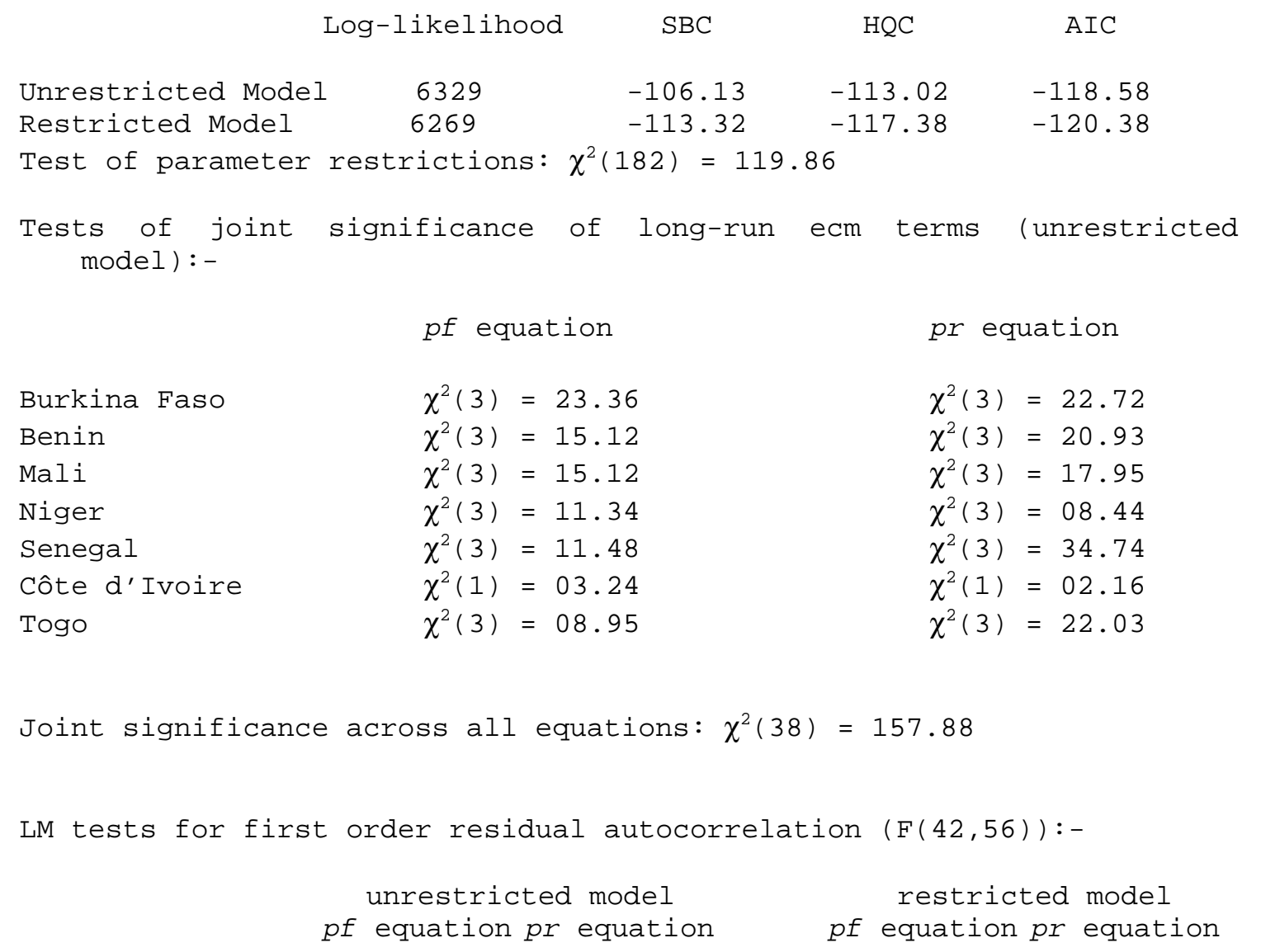

Burkina Faso

Benin

Mali

Niger

Senegal

Côte d'Ivoire

Togo

$\begin{array}{ll}0.57788 & 0.38329 \\ 0.31929 & 0.96914 \\ 0.31661 & 0.36285 \\ 0.32559 & 0.62101 \\ 0.45696 & 0.74553 \\ 0.21518 & 0.36119 \\ 0.39812 & 0.27811\end{array}$

0.57788

0.31661

0.39812
0.85153

0.59740

0.63464

0.48216

0.44802

0.46006

0.59139
0.33829

0.86053

0.62930

0.51252

0.68297

0.54314

0.35904

Model Forecast Error Tests (* = significant at 5\%) 